\title{
A Review of Visualisations in Agricultural Decision Support Systems: an HCI Perspective
}

\author{
Francisco Gutiérrez ${ }^{\mathrm{a}}$, Nyi Nyi Htun ${ }^{\mathrm{a}, *}$, Florian Schlenz ${ }^{\mathrm{b}}$, Aikaterini Kasimatic ${ }^{\mathrm{c}}$ \\ Katrien Verbert ${ }^{\mathrm{a}}$ \\ ${ }^{a}$ Department of Computer Science, KU Leuven, Leuven, Belgium \\ ${ }^{b}$ Geocledian GmbH, Am Wirtsanger 20, 84036 Landshut, Germany \\ ${ }^{c}$ Agricultural University of Athens, Athens, Greece
}

\begin{abstract}
Decision Support Systems (DSSs) are used in precision agriculture to provide feedback to a variety of stakeholders, including farmers, advisers, researchers and policymakers. However, increments in the amount of data might lead to data quality issues, and as these applications scale into big, real-time monitoring systems the problem gets even more challenging. Visualisation is a powerful technique used in these systems that provides an indispensable step in assisting end-users to understand and interpret the data. In this paper, we present a systematic review to synthesise literature related to the use of visualisation techniques in the domain of agriculture. The search identified 61 eligible articles, from which we established end-users, visualisation techniques and data collection methods across different application domains. We found visualisation techniques used in various areas of agriculture, including viticulture, dairy farming, wheat production and irrigation management. Our results show that the majority of DSSs utilise maps, together with satellite imagery, as the central visualisation. Also, we observed that there is an excellent opportunity for dashboards to enable end-users with better interaction support to understand the uncertainty of data. Based on this analysis, we provide design guidelines towards the implementation of more interactive and visual DSSs.
\end{abstract}

Keywords: decision support systems, human-computer interaction, information visualisation, precision agriculture

\footnotetext{
* Corresponding author

Email addresses: francisco.gutierrez@cs.kuleuven.be (Francisco Gutiérrez), nyinyi.htun@kuleuven.be (Nyi Nyi Htun), florian.schlenz@geocledian.com (Florian Schlenz), akasimati@aua.gr (Aikaterini Kasimati), katrien.verbert@cs.kuleuven.be (Katrien Verbert)
} 


\section{Introduction}

Decision Support Systems (DSSs) are designed to assist humans in making more effective decisions. In the field of agriculture, different stakeholders such as farmers, advisers and policymakers use software tools that facilitate farm management by gathering data from multiple sources, analysing these data and utilising a series of suggestions that are presented by different visual outputs. Many DSSs are designed to support the concept of precision agriculture (PA) which seeks to provide a holistic approach to assist farmers with optimising resources [1]. McBratney et al. [2] defined PA as the "kind of agriculture that increases the number of (correct) decisions per unit area of land per unit time with associated net benefits". Thus, PA research concentrates on enabling users to make the right decisions considering both space and time.

In the history of agricultural systems, user-driven data and model development has played an essential role in meeting users' analysis need for decision-support [3]. Still, models remain unfriendly, inside a black-box and behind DSS software. This black-box nature often leads to trust issues, notably when suggestions coming from a DSS fail [4]. Moreover, an increase in the use of farm sensors, high-tech harvesters and drones, among others, has created a massive amount of data that might be difficult for decision-makers to grasp [5]. Users, therefore, need additional tools for understanding and interpreting their data [6]. Visualisation is a powerful technique to address these issues and has demonstrated its usefulness in PA [7] to communicate uncertainty from both the data and the models [8]. Visualisation techniques have been used to assist users to better interact and understand data by aggregating, filtering, searching or otherwise sifting through and scaling down relevant information. Moreover, visualisations are often explicitly designed to assist our visual system in handling detail that might otherwise require significant cognitive effort. For instance, visualisations provide information that can be easily perceived, recognised and processed into inferences. In this sense, visualisations also offer short-term or long-term memory aids to reduce memory and cognitive load. Such support can make data, including potentially complex information, more easily consumable. As Rind et al. [9] suggest, visualisation tools and techniques "combine the processing power of modern computers with human cognition and visual abilities to better support analysis tasks".

In line with participatory DSS development, visualisations can be especially practical and useful when following user-centred design approaches [10]. In fact, a number of qualitative PA studies highlighted the importance of using a participatory-design approach $[11,12]$, where the farmer's perspective is used as the central focus of the design. A key goal of such an approach is to support complex data analysis by providing diverse visualisation techniques and adapting the tool according to the farmer needs [13].

A great number of visualisations and visual analytics tools have been proposed in the domain of agriculture with the aim to support the decision-making process. However, to the best of our knowledge, a comprehensive analysis of such tools, by considering their application areas, visualisation techniques and intended 
end-users, does not yet exist. Previous literature reviews in agriculture have focused on similar areas such as DSSs and PA, but not on visualisation techniques. For example, Kamilaris et al. [14] presented a survey on the recent practices of big data analysis in agriculture that would help farmers and companies to extract value from data, improving their productivity. This survey highlighted the opportunities of big data analysis for smarter farming. A different systematic review [15] highlighted the methodologies that can be used to support farmers in designing innovative agricultural production systems. In the context of precision agriculture, Imam et al. [16] reviewed design issues for wireless sensor networks and showed a comparison of different characteristics of humidity sensors, such as sensor type, their sensitivity and power consumption, which play a key role for wireless sensor networks for precision agriculture applications. As such, a number of reviews have addressed the issues surrounding DSSs and PA, but the use of visualisations in DSSs has yet to be understood.

To address this gap, in this paper, we review the use of information visualisation techniques in 61 articles that report their support for end-user decision-making. From an HCI (Human-Computer Interaction) perspective, we explore the design methodology behind the implementation of such systems and investigate the rationale behind the use of visual components in different application domains. HCI is a discipline in which users as well as technology and environment are emphasised in the design process [17]. For example, paying little attention to the environment could result in the DSS being unfit for the intended environment. A recent study [18] explored the reasons behind the lack of interest by farmers in the computer-based support systems and highlighted the importance of HCI perspectives when designing DSSs. The study also found clear benefits of designing a DSS that is easy to use, fits the existing workflow of users, performs well and incubate trust [18], which are some of the most commonly accessed metrics of HCI research. We had two specific goals in this review: our first goal was to examine user interaction with DSS for agriculture (i.e., input to the system, output from the system and other interface factors) in order to identify design features that go into the making of effective DSS. Our second goal was to gain insight into the evaluation of DSS, as well as to learn from these evaluations to identify opportunities for future research. To guide this work, we have defined our research questions as follows:

- RQ1: What visualisation techniques are being used across different domains in agriculture?

- RQ2: How are these visualisations being used by end-users to make decisions?

- RQ3: What is the role of uncertainty in the visualisation tools that support decision-making?

- RQ4: What is the role of HCI in the design and development of visualisation tools to support end-user decisions? 
The contributions of this paper are the following: first, we present an extensive overview of visualisation and visual analytics techniques that have been elaborated in the agriculture field, highlighting the potential of DSSs and their use of visualisations for decision-making in agricultural contexts. Second, we present an analysis of a wide range of characteristics, including visualisation techniques that are commonly used, how data is captured and how these systems have been evaluated. Based on this analysis, we outline guidelines for the design of DSSs as well as directions for future research for this area.

\section{Method}

In this section, we first elaborate the method employed for the selection of articles/papers for our systematic review. We also define the different categories that were used for coding the existing tools.

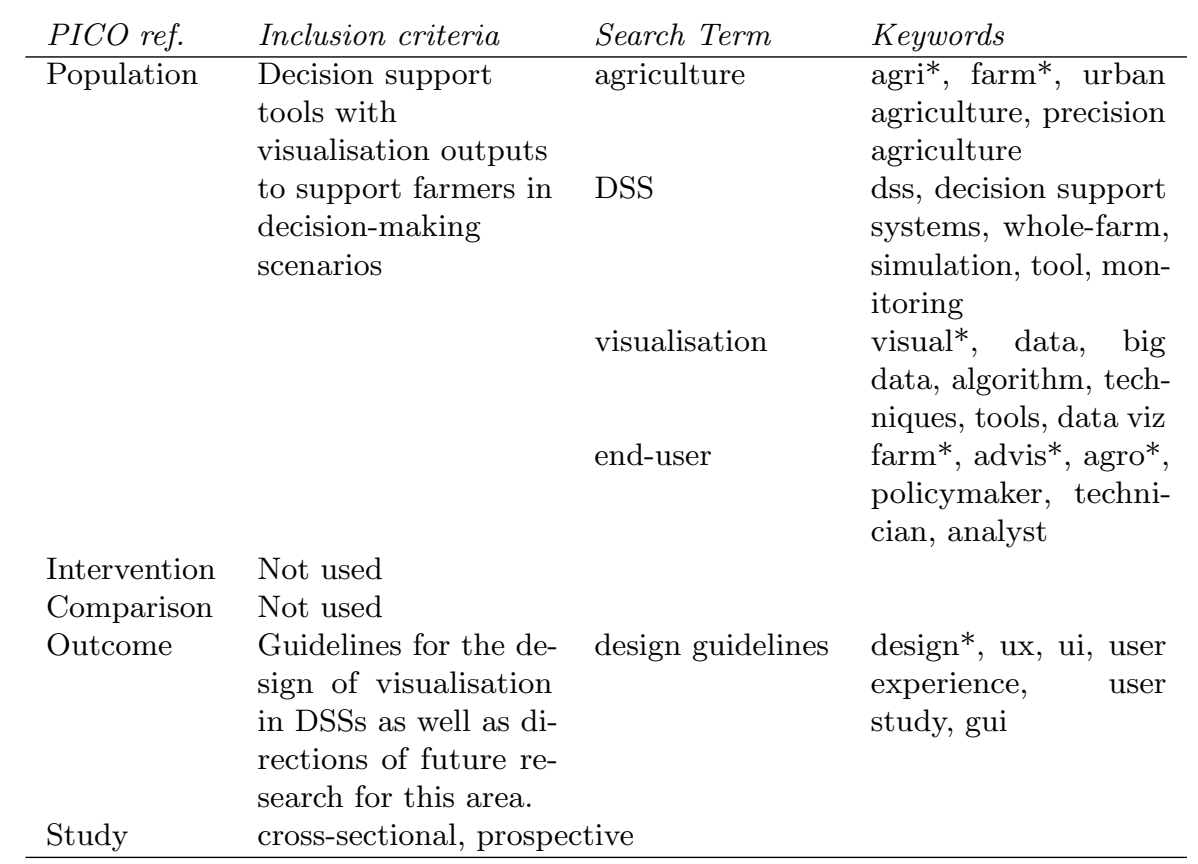

Table 1: Overview of the search strategy, keywords identified and search-terms, based on the PICO framework.

\subsection{Eligibility Criteria}

This review includes articles that investigated or reported the usage of DSSs involving visualisation techniques to support end-users in the field of agriculture. The eligibility criteria were specified according to the PICO framework (Table 1), stated in the preferred reporting items for systematic review and meta-analysis statement [19]. 
No restrictions were placed on the date. All the included papers were written in English. The population was targeted to all articles reporting end-users (i.e. farmers, policymakers or advisers) using any kind of decision tools, (i.e. demos, proof-of-concept tools, dashboards and simulations) in the agriculture domain and being supported by the use of any type of visualisation for decision-making. DSSs were included without restrictions on the platform of use (i.e. desktop, web-browser or mobile applications). Literature was included if they added a clear description of the DSS, stating the data input, collection and outcome for any end-user involved in the agriculture domain (i.e. farmers, advisers, policymakers). Articles describing the use of visualisations in text or figures were included. Papers that reported the design process of the tool and user studies regarding visualisation techniques were included and analysed in detail separately.

\begin{tabular}{l} 
database \\
\hline Google Scholar \\
ScienceDirect \\
Field Crops Research \\
Agriculture, Ecosystems and Environment \\
Agricultural and Forest Meteorology \\
Advances in Agronomy \\
Applied Soil Ecology \\
Precision Agriculture \\
Computers and Electronics in Agriculture \\
IEEE Xplore
\end{tabular}

ACM Digital Library count search query

( 76) agriculture farm user study tool UX UI design visualisation DSS "big data"

(148) \{FilterBy: JournalName\}, (242) \{Keywords: agri*, farm*, (179) "urban agriculture",

"precision agriculture", DSS,

simulation, tool, monitoring (274) visual*, data, "data viz", (43) farm*, advis*, agro*, (476) design*, ux, ui, "user experience", "user study" \{SearchBy: FullTextAndMetadata\} $\{$ Keywords: agri*, farm*, "precision agriculture", DSS, visual*, data, tool, data viz, farm*, advis*, agro*, design*, ux, ui, "user experience", "user study"

\{SearchBy: AnyField\}

\{Keywords: agri*, farm*, "precision agriculture", DSS, visual*, data, tool, data viz, farm*, advis*, agro*, design*, ux, ui, "user experience", "user study" 


\subsection{Search Strategy}

A scoping exercise to nail down search keywords was conducted in the Google Scholar and ScienceDirect databases in May 2018. The keyword identification was complemented by using keyword services such as Google Keyword Planner and Keyword Tool. The produced keywords are presented in Table 1. Using the defined keywords, hand searching (i.e., a method of manually examining a paper to identify all eligible criteria [20]) of relevant authors and articles was conducted in Google Scholar. As Google Scholar provides a broad result of papers, we used the advanced search functionality for initial searches and narrowed down the search using the specific keywords defined in the eligibility criteria section, and listed in Table 2. Journals in the agriculture domain were identified using ScimagoJR ${ }^{1}$. The search of papers within the identified journals was done in the ScienceDirect platform. Results from the search are presented in Table 2.

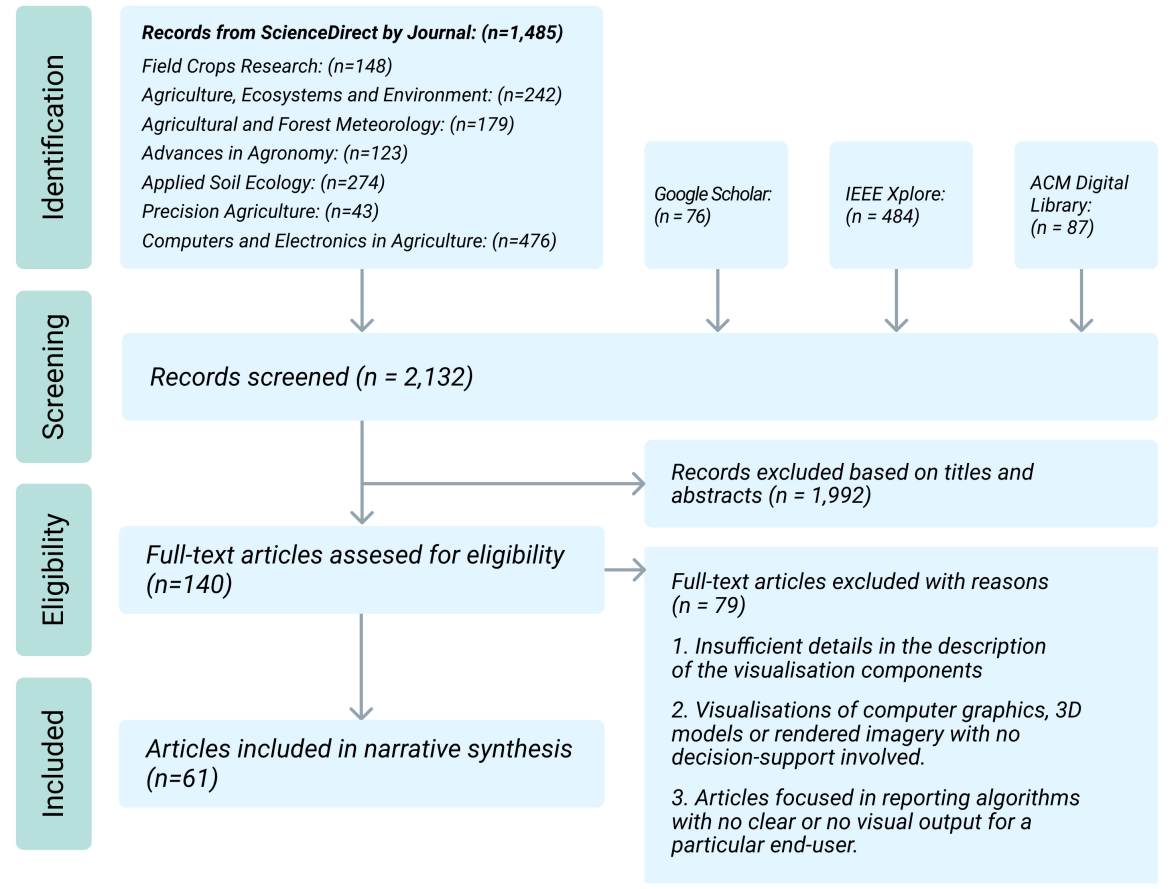

Figure 1: Flow diagram illustrating the literature selection process.

\subsection{Literature Selection}

Results from each database were imported into Mendeley $(n=2,132)$. Titles and abstracts were screened, excluding those who were not relevant to our research

\footnotetext{
${ }^{1}$ https://www.scimagojr.com/
} 
and/or did not meet the previously defined eligibility criteria. Afterwards, the remaining articles were retrieved and assessed for eligibility at full-text ( $\mathrm{n}=$ 140). The process of paper selection is illustrated in Figure 1. In summary, the search identified 2,132 papers, from those, only 140 documents were retrieved and reviewed in full-text from this initial set based on our criteria. This narrowed the scope of this literature review to sixty-one articles.

\subsection{Data Extraction}

Data from the included articles were coded and extracted in a spreadsheet designed for this review: https://goo.gl/SeJDdV. The 61 papers included in this review were coded based on the following main categories: end-user, tool type, development status, platform, the visualisation technique, data source, research domain and evaluation. At the beginning of this stage, an inter-coder reliability assessment was conducted between the researchers using Cohen's kappa [21]. A random selection with $20 \%$ of the papers was listed in a spreadsheet and coded following the defined coding categories and subcategories. The decisions made by the second researcher were compared against the first, generating Cohen's Kappa statistics. The statistics revealed a substantial agreement between the researchers, $k=0.76$ (95\% CI, 0.62 to 0.89$), p<0.001$. Disagreements were discussed and resolved. Consistency in coding was kept throughout the remaining reviewed papers.

Categories and subcategories were identified based on our research questions and objectives, most of them emerged as common themes derived from the articles in this review, for all the categories we used both open and closed coding approaches (see Table 3 for an overview of the categories). In the following subsections, we briefly describe these categories.

\subsubsection{End-Users}

Stakeholders are the main targets of DSSs in agriculture. In this review, we identified four types of stakeholders: farmers, domain experts (farm advisers or agronomists), academic researchers and policymakers (see Table 3). In this review, we used the end-user category to identify the types of visualisations that are targeted at specific types of stakeholders.

\subsubsection{Tool Type}

Some DSSs are designed to provide a simulation approach where farmers can walk-through simulated farming scenarios to explore and better understand their practices (e.g. [22]). This approach can also help leverage learning of farmers. Unlike the simulation approach, there are DSSs that have been designed for practical applications in real farms. Such systems provide decision support solutions for a particular decision-making scenario (e.g. irrigation scheduling, fertiliser application, etc.). In addition, there are systems that provide farmers with necessary tools for the planning required for the whole farm. As such, we categorised the papers into three tool types based on their approach: simulation, real practice and whole-farm management. 


\begin{tabular}{|c|c|c|}
\hline category & subcategory & short definition \\
\hline \multirow[t]{4}{*}{ End-user } & farmer & $\begin{array}{l}\text { A farmer primarily engages in farming, can be } \\
\text { a land owner or land manager. }\end{array}$ \\
\hline & domain expert & $\begin{array}{l}\text { A farm adviser or agronomist concerned with } \\
\text { guiding farmers and with the health and well- } \\
\text { being of crops. }\end{array}$ \\
\hline & academic & $\begin{array}{l}\text { An individual related to education and with } \\
\text { research interests. }\end{array}$ \\
\hline & policymaker & $\begin{array}{l}\text { Involved in the formulation of policies often } \\
\text { working for the government (e.g. rural exten- } \\
\text { sion technicians). }\end{array}$ \\
\hline \multirow[t]{3}{*}{ Tool type } & simulation & $\begin{array}{l}\text { A system that simulates farming scenarios al- } \\
\text { lowing users for self-reflection, exploration and } \\
\text { discovery of new perspectives and scenarios. }\end{array}$ \\
\hline & real practice & $\begin{array}{l}\text { Software that can be used in real farming prac- } \\
\text { tices for a particular decision-making scenario } \\
\text { (e.g. irrigation scheduling, fertiliser application, } \\
\text { etc.). }\end{array}$ \\
\hline & whole-farm & $\begin{array}{l}\text { A system that provides a holistic approach for } \\
\text { farm management based on short and long- } \\
\text { term vision of a farmer. }\end{array}$ \\
\hline \multirow[t]{3}{*}{ Dev. status } & concept & The tool is a proof-of-concept \\
\hline & prototype & The tool is a working prototype \\
\hline & production & $\begin{array}{l}\text { The tool is available to use and accessed by } \\
\text { many users. }\end{array}$ \\
\hline \multirow[t]{2}{*}{ Platform } & mobile & Intended to work in mobile devices \\
\hline & desktop & Intended to work in desktop systems \\
\hline Visualisation & & $\begin{array}{l}\text { The visual technique used to represent and } \\
\text { communicate data }\end{array}$ \\
\hline Data Source & & Type of data collected and used by the tool \\
\hline App. Domain & & $\begin{array}{l}\text { The application domain where the tool was } \\
\text { used }\end{array}$ \\
\hline \multirow[t]{3}{*}{ Design approach } & participatory & $\begin{array}{l}\text { An approach that involves all stakeholders in } \\
\text { the design process to satisfy requirements and } \\
\text { usability. }\end{array}$ \\
\hline & focus group & $\begin{array}{l}\text { A small group of people whose opinions are } \\
\text { studied to discover their attitudes towards a } \\
\text { product or service. }\end{array}$ \\
\hline & iterative & $\begin{array}{l}\text { A design methodology based on a cyclic } \\
\text { method of prototyping, developing and evalu- } \\
\text { ating a product. }\end{array}$ \\
\hline \multirow[t]{4}{*}{ Evaluation } & observation & $\begin{array}{l}\text { A study to understand user behaviour by ob- } \\
\text { serving user interactions with a system. }\end{array}$ \\
\hline & questionnaire & $\begin{array}{l}\text { A method to gather feedback from users by } \\
\text { administering a set of written questions. }\end{array}$ \\
\hline & interview & $\begin{array}{l}\text { A method to gather feedback from users by } \\
\text { verbally asking questions. }\end{array}$ \\
\hline & workshops & $\begin{array}{l}\text { A method to gather feedback from a group of } \\
\text { users. }\end{array}$ \\
\hline
\end{tabular}

Table 3: Definitions of categories and subcategories for data extraction. 


\subsubsection{Development Status}

DSSs are often evaluated at different stages of the development life circle. Thus, although certain papers present the systems that are currently being applied in real farms, there are others that are under development or at a concept stage. We used this category to identify the status of the application and understand the usage of visualisation at different levels. Subcategories include concept, prototype and production.

\subsubsection{Platform}

Since the scale of agricultural operations has increased over the years, DSSs are required to support on-the-fly access and in-field decision-making [23]. Thus, many researchers have started looking into the use of different devices (i.e. desktop or mobile). The systems themselves and visualisation requirements can differ according to the platform. In this review, we identified the papers that are intended for mobile and/or desktop uses.

\subsubsection{Visualisation Techniques}

One main goal of this review was to identify visualisation techniques that are proposed for agricultural decision support systems. Visualisation techniques may vary according to the needs of the users, application domain, visual literacy, etc. With this category, we identified an exhaustive list of visualisation techniques that are used to display agricultural data and predictions.

\subsubsection{Data Source}

Outputs of DSSs are driven by data [24]. The type of data collected and how they are utilised play an important role in providing optimal decisions and can vary depending on the decision-making requirements. Thus, we identified data sources of the selected DSSs.

\subsubsection{Application Domain}

There are diverse sub-domains in agriculture, some of which include: wheat production, irrigation management, crop management, etc. Depending of the domain, decision requirements can also vary vastly. Since our initial analysis showed that DSSs have been proposed for many sub-domains of agriculture, we identified the application domain of each DSS.

\subsubsection{Design Approach}

The design stage has been identified as one of the critical steps in the development of visualisation tools and agricultural DSSs [25]. It also plays an important role in the adoption of the system [26]. Thus, significant efforts have been put into applying user-centred approaches for developing DSSs [27]. We categorised the selected DSSs based on the following user-centred design approaches: participatory, focus group and iterative. A brief definition for each of these categories has been provided in Table 3. It is important to note that the design approach generally defines a framework for evaluating a system. Various 
evaluation methods maybe used under a selected framework. These evaluation methods are described in Section 2.4.9.

\subsubsection{Evaluation Methods}

Evaluation is an important part of the software development life circle as it ensures that all the requirements of the software are met. As mentioned in Section 2.4.8, different evaluation methods can be used under a selected design framework. Our initial analysis showed that a number of evaluation methods have been used by previous work in agriculture. Thus, we identified DSSs based on the following evaluation methods: observation, questionnaire, interview and workshop. A brief definitions for these categories can be found in Table 3. In general, user observations are conducted "in the wild" where users are typically allowed to explore a given tool freely. Interactions with the tool are observed and recorded. In certain cases, questionnaires may be administered to users who then provide written answers to a set of questions which can include both open- and close-ended questions. Unlike asking the questions verbally as in interviews, questionnaires demand less effort from the questioner and provide structured sets of answers. On the other hand, interviews involve delivering both questions and answers verbally. Interviews allow the questioner to capture in-depth feedback and to pose further questions which is not possible with the questionnaire approach. Workshops, unlike interviews, involve a group of users answering to a set of questions which are typically introduced by the questioner. Workshops create a great environment to capture rich opinions from users by allowing them to discuss the questions and come up with solutions.

\section{Analysis}

We analysed the selected papers based on the nine categories presented in Table 3 as explained above. An overview of the number of papers identified within each category is shown in Figure 2. In the following subsections, results of our analysis are presented.

\subsection{Application Domain}

In this section, we provide an overview of DSSs that have been elaborated in various application domains and demonstrate how they have been applied to assist with decision support tasks. Although many of the systems are grouped by their application domain, some fall under various domains, as illustrated in Figure 3. Although this figure is by no means exhaustive, it provides insights into the typical cross-domain supports of current DSSs in agriculture. A complete list of DSSs under each application domain is presented in Table 4.

\subsubsection{Viticulture}

Visualisations in viticulture enable a better vineyard monitoring, reducing costs and at the same time, generating a more transparent representation of the existent variability in the vineyard, which is valuable for the optimisation 


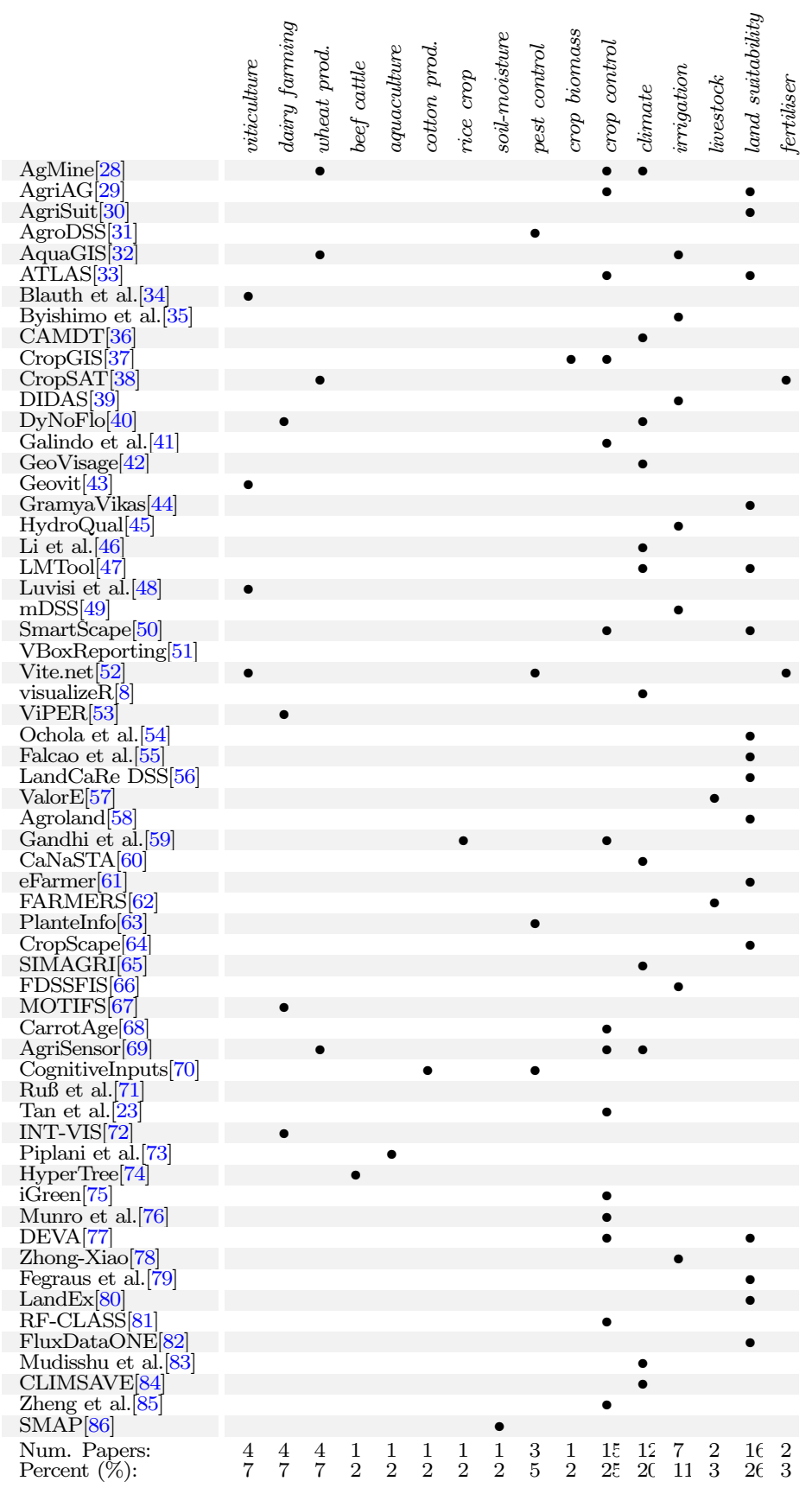

Table 4: DSSs categorised by different application domains. 


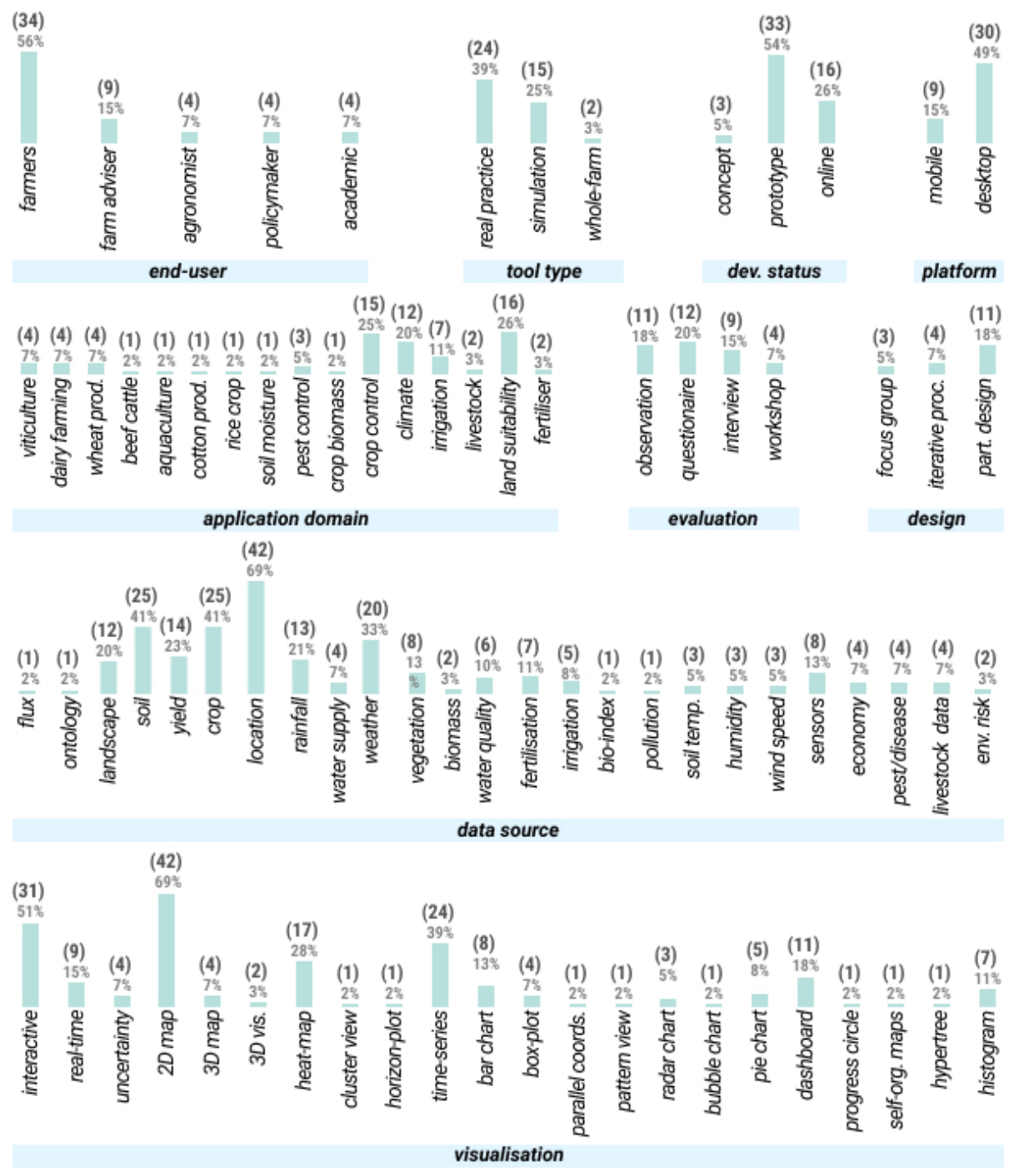

Figure 2: Overview of the data extraction results by categories. The number of papers identified for each category is indicated between parenthesis.

of the harvest and producing high-quality grapes [87]. Vite.net [52] is a DSS for crop management of vineyards (Figure 4a). Using sensors, the system shows visual information about soil water content to help farmers monitor adequate water levels. Decision support modules provide information about vine growth, pest control and diseases in grape berries. The visualisation of real-time information supports farmers to make informed decisions and maintain a record behind each management action. Blauth and Ducati [34] introduced a map visualisation of the land usage in vineyards (Figure $4 \mathrm{~b}$ ). The system 


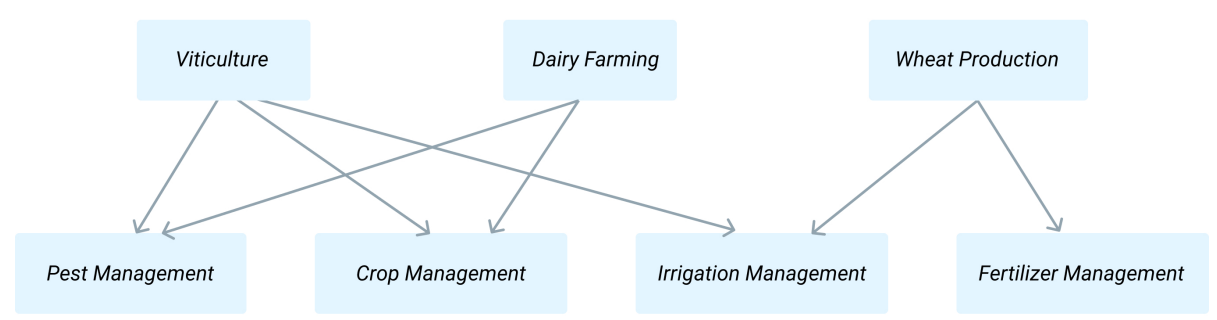

Figure 3: Example application domains and cross-domain supports of DSSs.

monitors grape variety, production and inventory information, using a map to indicate vineyards, vegetation, bare soil or nearby urban areas. Geovit [43] provides support to farmers at a landscape level (Figure 4c) with an interactive dashboard that allows the selection and comparison of areas of interest together with multiple data layers on top of a map.

\subsubsection{Dairy Farming}

According to an annual report published by United States Department of Agriculture ${ }^{2}$, feeding animals for dairy farming is one of the highest expenses for dairy producers across the states. In order to optimise productivity, dairy producers focus on formulating diets based on the growth rate, milk production and reproduction. Thus, DSSs have also become widely popular in dairy farming. ViPER [53] is a DSS that provides a visualisation of the agricultural land to manage microbial pollution risks (Figure 5a). A participatory design approach was used to engage with stakeholders in order to create a user-friendly system for guiding on-farm risk assessment. The resulting tool visualises patterns of E. coli in space and time. DyNoFlo Dairy [40] is a DSS intended for producers and regulatory agencies. The main purpose of this tool is to integrate nutrient budgeting, crop and optimisation models to assess nitrogen leaching from dairy farm systems. The user interface of DyNoFlo Dairy provides a graphical representation of all system modules and their connections, allowing users to interact with different models in order to optimise nitrogen leaching and profit (Figure 5b).

\subsubsection{Wheat Production}

Wheat is grown on more land area than any other commercial crop and continues to be the most important food grain source for humans. Its production leads all crops, including rice, maize and potatoes. We found four tools ([28], [32], [33], [38]) that visually support end-users in the wheat production domain. AgMine [28] provides valuable information for Western Australian wheat growers, using diverse visualisation techniques to illustrate seasonal rainfall and yield

\footnotetext{
${ }^{2}$ https://www.ers.usda.gov/data-products/milk-cost-of-production-estimates/
} 


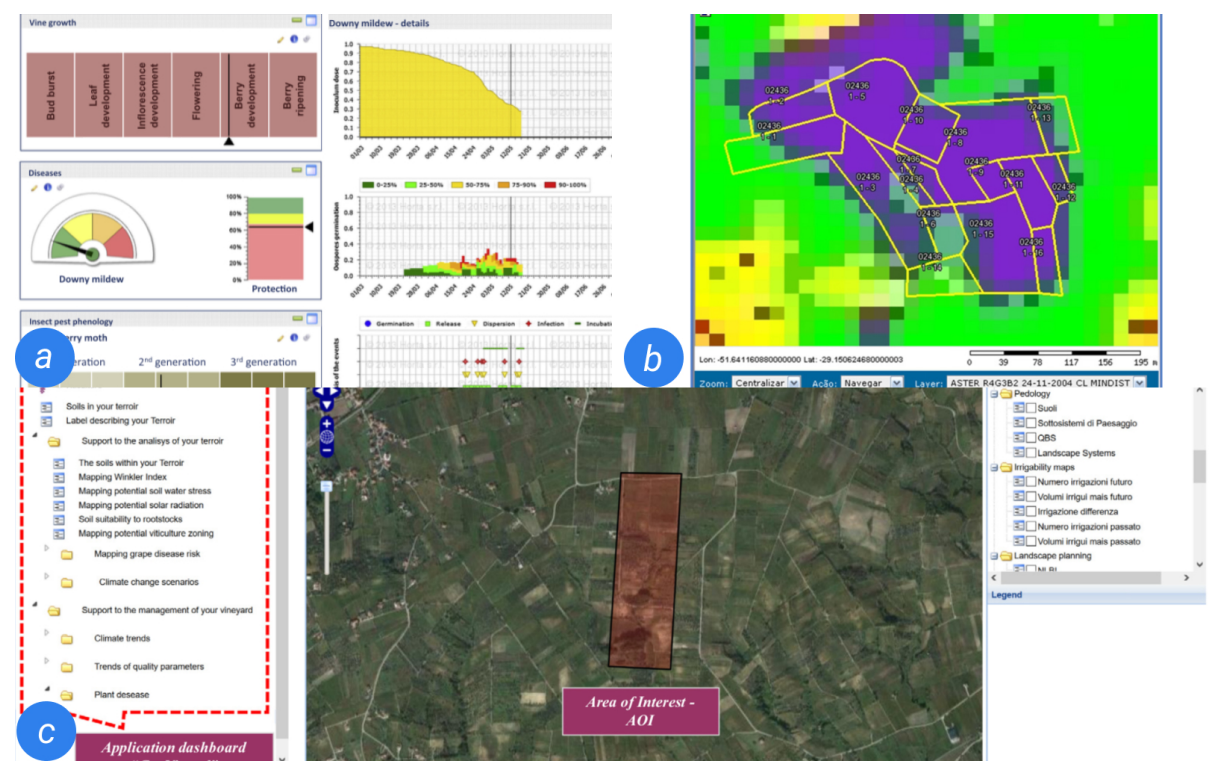

Figure 4: The use of visualisation in the viticulture domain: a) Vite.net [52], b) Blauth and Ducati [34], c) Geovit [43]

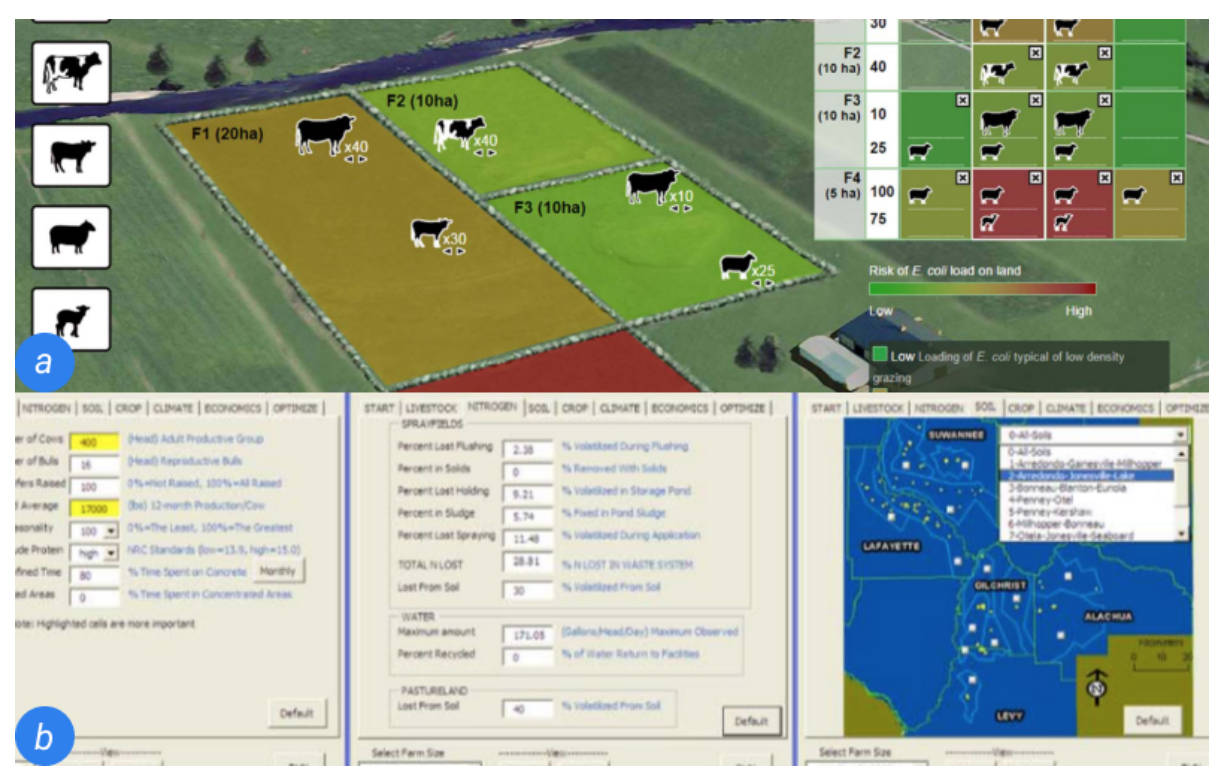

Figure 5: The use of visualisation in dairy farming. a) ViPER [53], b) DyNoFlo [40] 


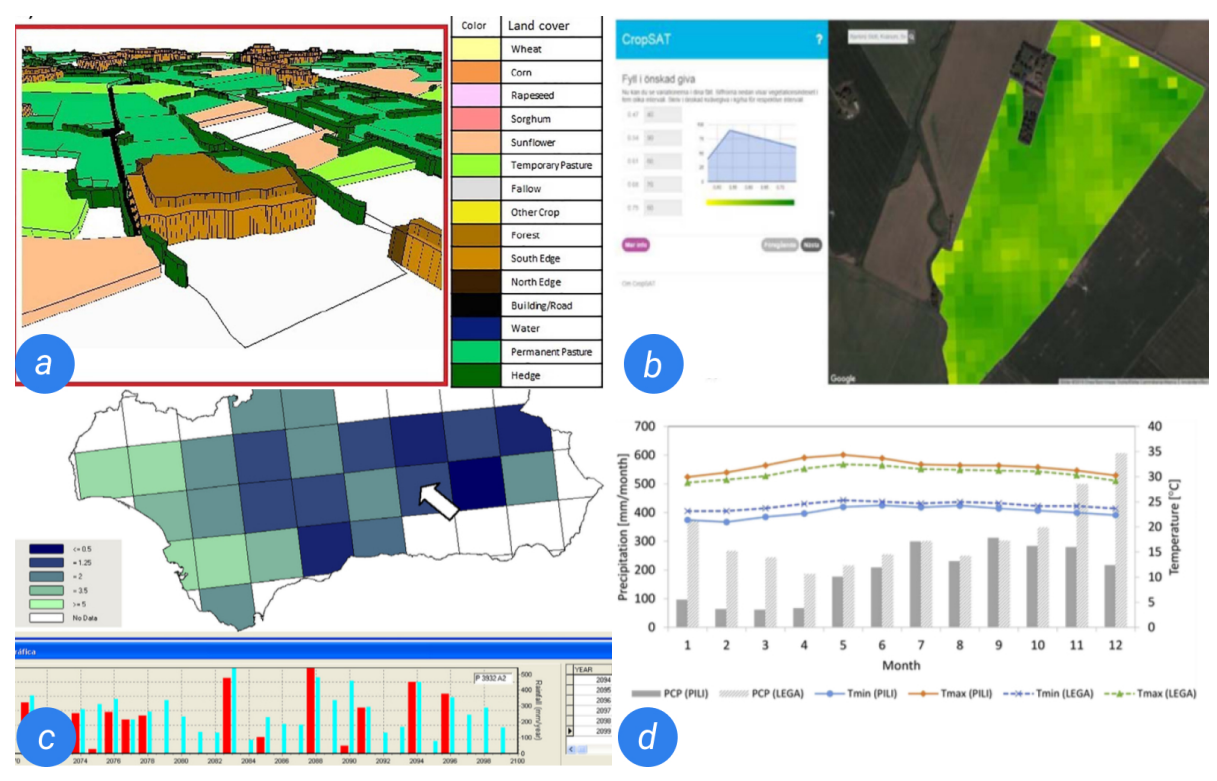

Figure 6: The use of visualisation in wheat production a) AgMine[28], b) AquaGIS/AquaCrop [32], c) ATLAS [33], d) cropSAT [38]

production (Figure 6a). AquaCrop [32] provides simulation analysis towards the impact of climate change on wheat yield in Southern Spain by visualising yield and rainfall (Figure 6b). ATLAS [33] simulates crop availability at the landscape scale by visualising in 2D and 3D maps different crop scenarios in relation to pests, diseases and biological control (Figure 6c). cropSAT [38] is a DSS to visually analyse nitrogen fertilisation of winter wheat using satellite images: farmers can recognise and explain visualised variation in the crop biomass (Figure 6d).

\subsubsection{Pest and Disease Control}

Pest control is a vital process in the agricultural business, as pests and diseases can lead to important economic and ecological losses [88]. A number of DSSs have focused on providing support for farmers to identifying and treating $([52,31])$ a particular pest (see Figure 7). CognitiveInputs [70] (Figure 7a) is an interactive tool aimed for cotton growers that allows them to explore weed management decisions while considering uncertainties under climate conditions. Designed as an extension for existing farm management systems, AgroDSS (Figure 7b) [31] uses data mining and statistical methods to make predictions for simulated scenarios and to better understand the dependencies within a domain. This includes identifying pest populations and species. AgroDSS uses time-series graphs to visualise such data. Vite.net (Figure 7c) [52] is a comprehensive farm management system that can also visually represent pest occurrences over the season. Time-series graphs are used to show in-depth information regarding a disease, an infection chain and/or infection severity. Further decision support 


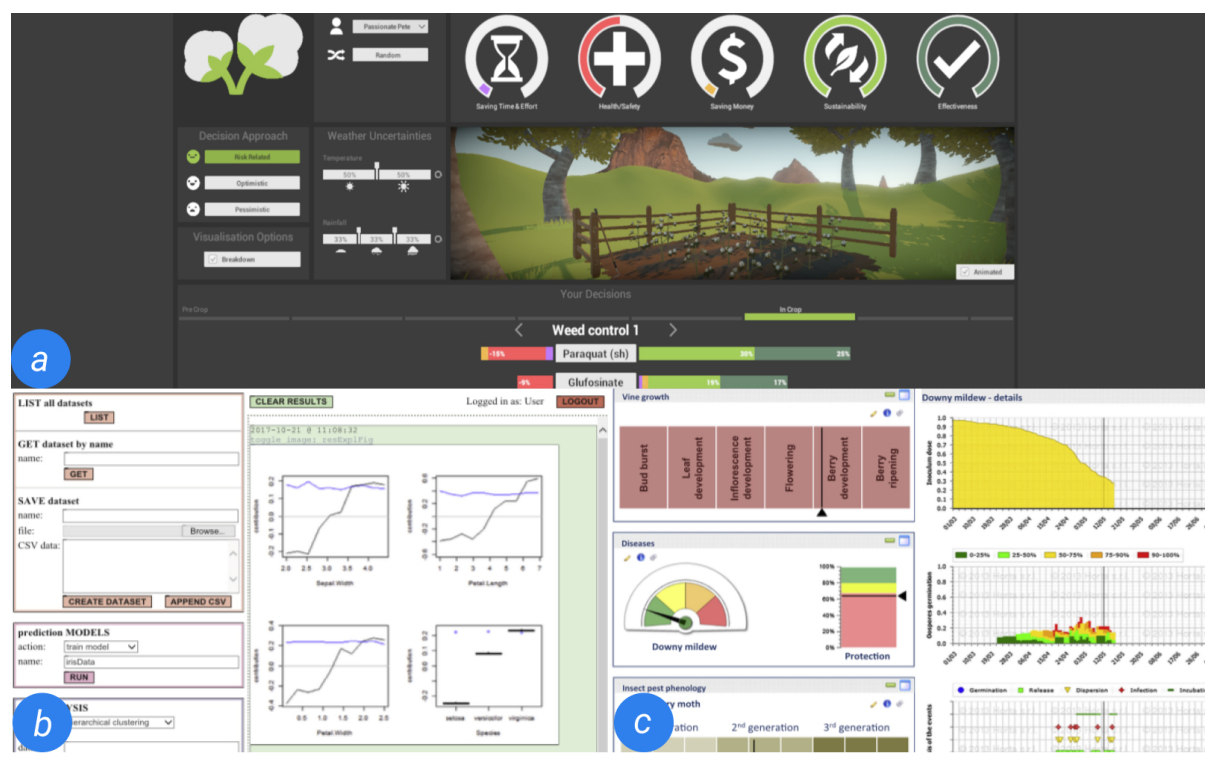

Figure 7: The use of visualisation in pest and disease control. a) CognitiveInputs [70], b) AgroDSS [31], c) Vite.net [52]

is provided for treatment plans using a decision tree. In addition, a dashboard shows alert levels of a disease and protection of the last fungicide spray against diseases.

\subsubsection{Irrigation Management}

Irrigation advisory services provide the farmers with assistance in irrigation scheduling knowledge, considering crop water conditions in different crops, optimising production and cost-effectiveness. Visualisations support farmers with a better overview of water distribution to their crops by showing moisture content, water uptake, etc. Such views allow farmers to adjust their irrigation process depending on the soil, farm area and season in order to optimise crop production. As an example, the tool designed by Byishimo and Garba [35] uses real-time data collected from in-field sensors to produce live visualisations allowing farmers to monitor and process information about the soil, temperature and irrigation. Interaction is limited as users can only hover over the time-series visualisation to see annotations indicating details about the data over time (Figure 8a). Another example is DIDAS [39], a tool that allows to evaluate a farm based on a number of inputs such as soil, evaporation, plant resistance and land structure and assists with the design and scheduling of drip irrigation systems (Figure 8b). By visualising water flow, DIDAS can assist farmers in taking decisions about irrigation schedules under conditions where water is a crucial limiting factor in crop productions. HydroQual [45] uses a dataset consisting of sequences of biological indices and physico-chemical values for geo-localised river stations and allows experts to visually analyse river water quality of different geographical 


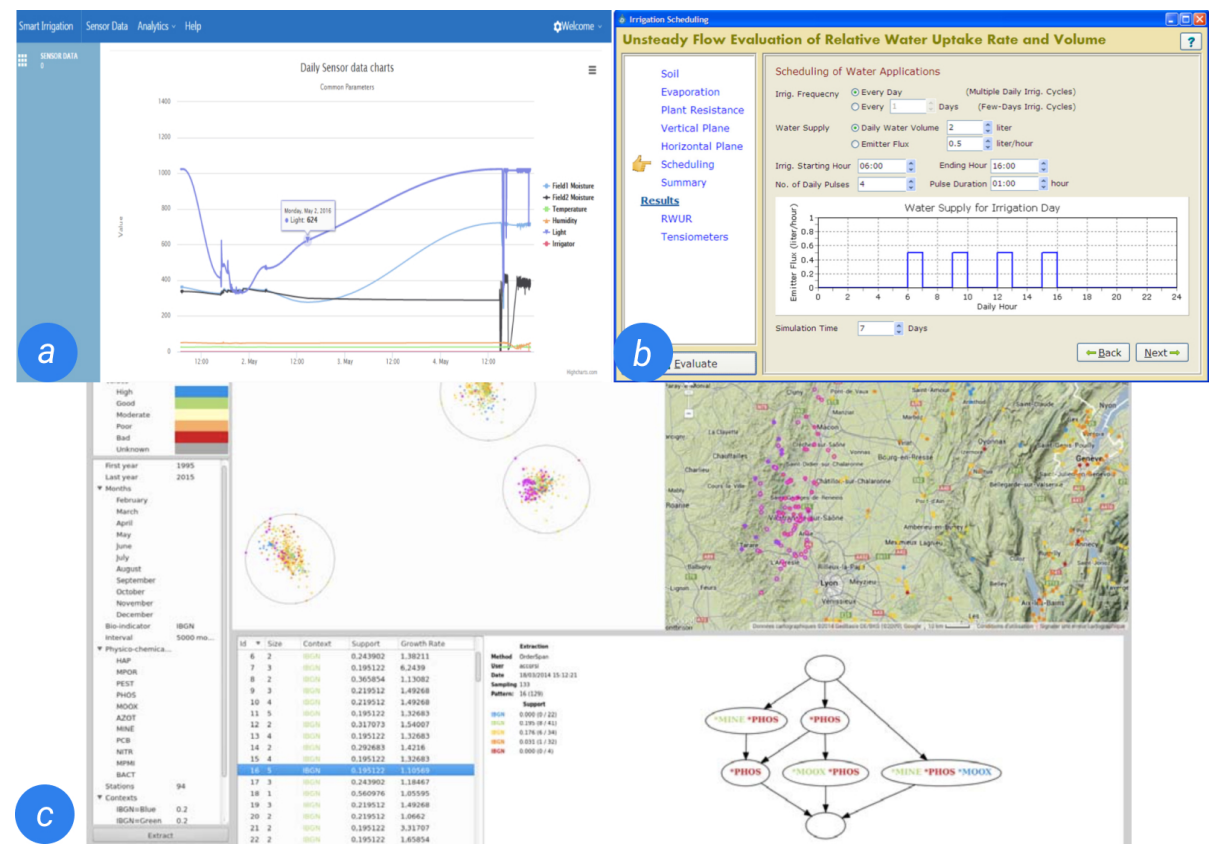

Figure 8: The use of visualisation in irrigation management. a) Byishimo and Garba [35], b) DIDAS [39], c) HydroQual [45])

areas (Figure 8c).

\subsubsection{Crop Management}

Crop production is deeply dependent on climate conditions, diseases and pests, making it essential to provide farmers with risk management technology. AquaGIS (Figure 9a) [32] is a visualisation tool that uses AquaCrop, a crop growth model, to simulate results of crop management in multiple fields and seasons. AquaGIS features visualisation modules that facilitate the presentation of spatial data. It allows an efficient visualisation in a map using different colours that facilitate spatial visualisation. An interactive component allows interaction between different maps that describe the evolution over time of the results provided by AquaCrop. AgMine (Figure 9b) [28] is a DSS that comprises multiple components of statistical analysis powered by visualisation modules. Visualisation is used in this tool as a powerful technique for geo-spatial analysis, climate and crop-yield mapping. With the proposed framework, farmers can use the visualisations to detect seasonal patterns of rainfall and see the effects on various scenarios comparing dry and wet years in crop production.

\subsubsection{Fertiliser Management}

The aim of precision agriculture is to optimise farm outputs while preserving resources [89]. Thus, fertiliser management plays an important role in precision 


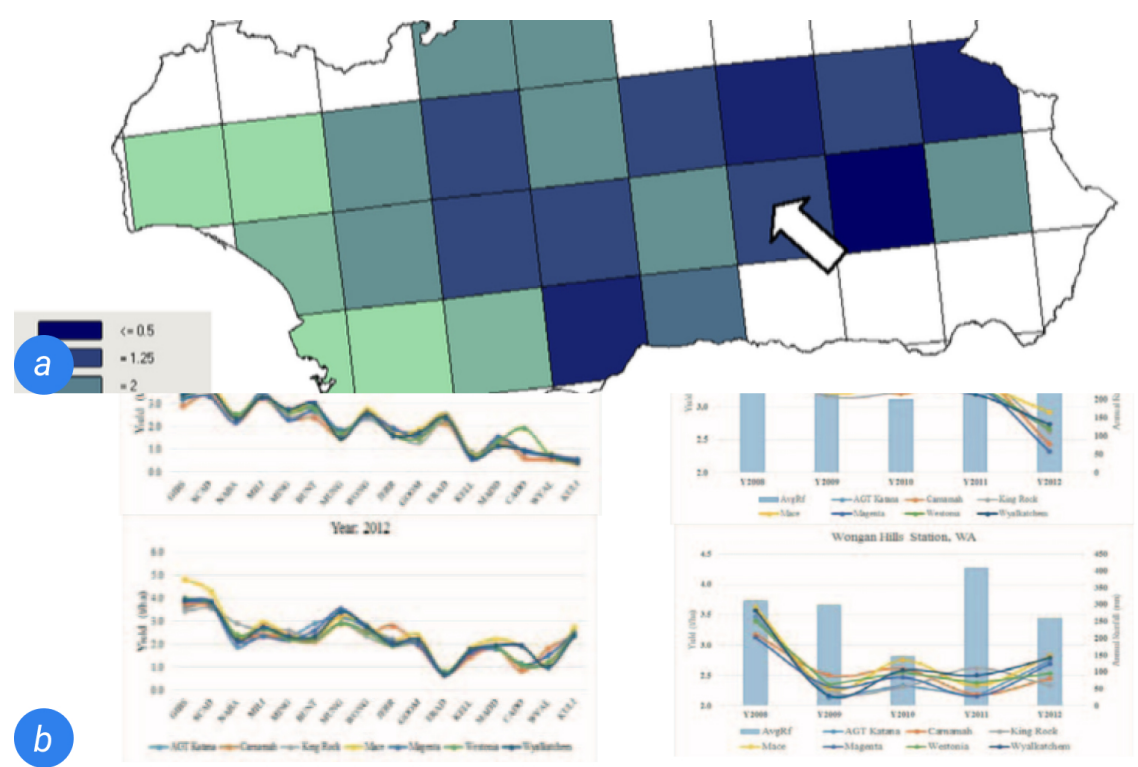

Figure 9: The use of visualisation to support crop management. a)AquaGIS [32] b) AgMine $[28]$

agriculture. CropSAT (Figure 10) [38] is a tool developed for calculation of variable rate application files for nitrogen fertilisation from satellite images. The images generated in CropSAT show visual representations of crop biomass variation, which is difficult to achieve by just walking or driving in the field.

\subsubsection{Weather Prediction and Climate}

Weather forecast is a big challenge in the practical application of seasonal predictions in different economic sectors [8]. Fortunately, interactive visualisation is well known for facilitating the analysis of probabilistic predictions under uncertainty [90, 91], particularly towards non-expert users [92]. An example tool, Geovisage [42], is a web-based decision support system designed for farmers that displays graphs of current sensor data from several weather stations. The tool visualises real-time data in a time-series plot offering a quick view of recent weather conditions where time periods and different weather stations are compared; a table provides extra details with statistical information (Figure 11a). CAMDT (Figure 11b) [36] is another example that aims to facilitate probabilistic seasonal weather forecasts. The tool provides a user interface to help decisionmakers adjust their crop and water management practices that may improve outcomes given the expected weather condition of the growing season. It provides "what-if" scenarios where the forecast is presented for visual comparison.

\subsection{End-Users}

While the majority of tools we reviewed are designed to support farmers, there are some that also support other end-users including domain experts 


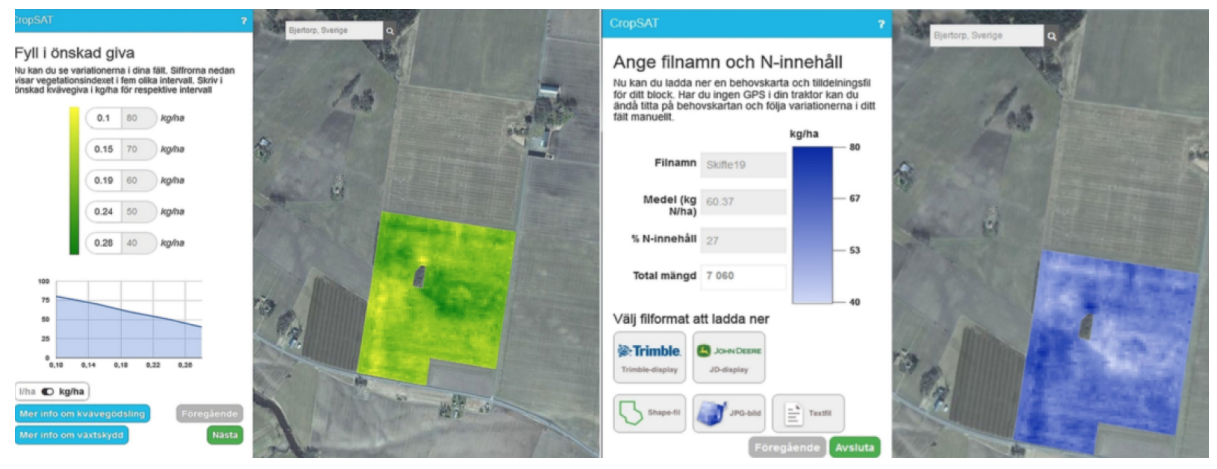

Figure 10: CropSAT [38], an example of visualisation in fertiliser management

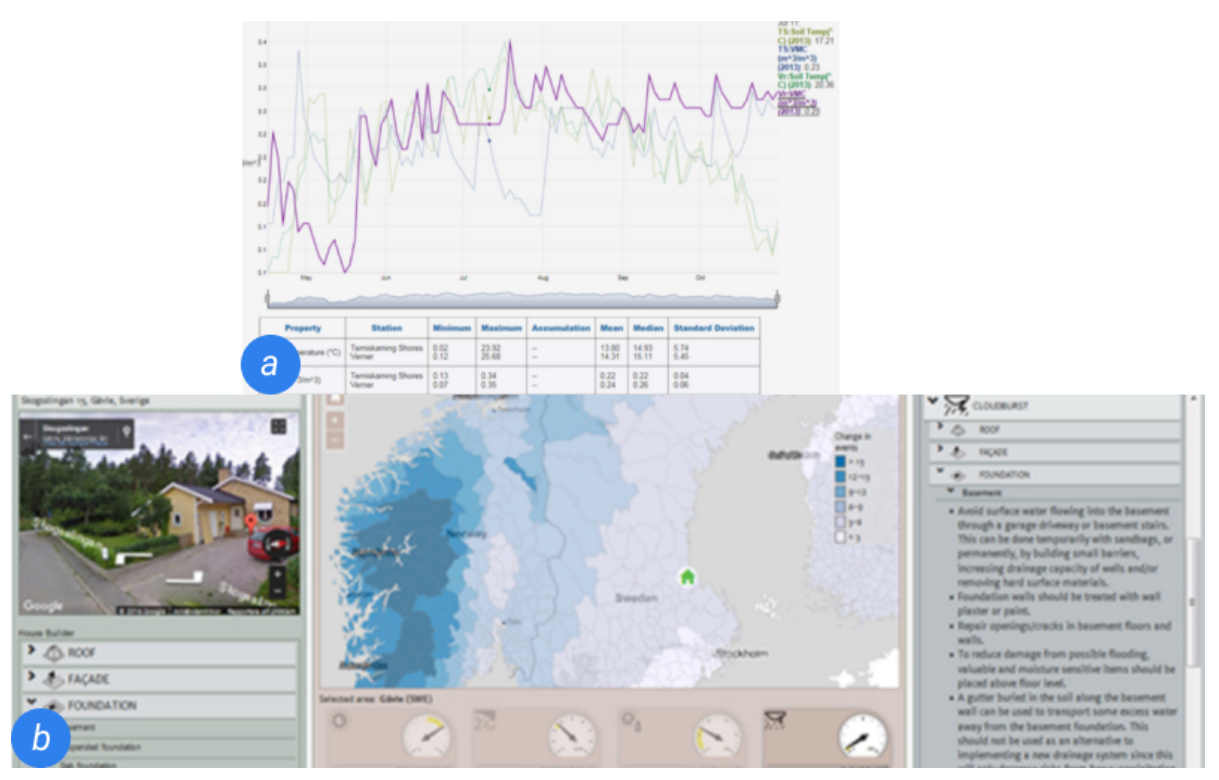

Figure 11: The use of visualisation in weather forecast. a) Geovisage [42], b) CAMDT [36]) 
(farm advisers and agronomists), policymakers and academic researchers. In this section, we present our findings of tools that have been designed to help different stakeholders in agriculture. A comprehensive list of these tools is presented in Table 5 .

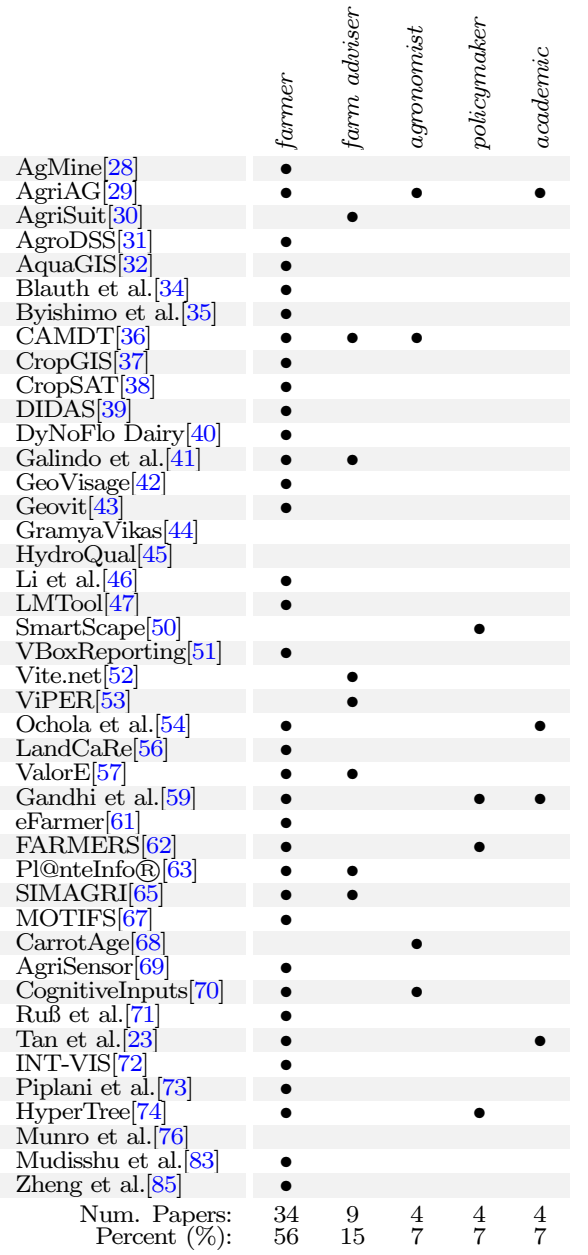

Table 5: Types of end-users reported in the different DSSs.

\subsubsection{Farmers}

We discovered that a large number of tools in agriculture (34 out of 61) are designed for farmers. These tools focus on assisting farmers with various aspects of farming. The majority of the tools used one or more visualisation techniques to help the farmers better understand the status of their farm and crops and to be able to make accurate decisions regarding irrigation schedules (Figure 8), fertiliser applications (Figure 10), pest control (Figure 7), etc. Details 


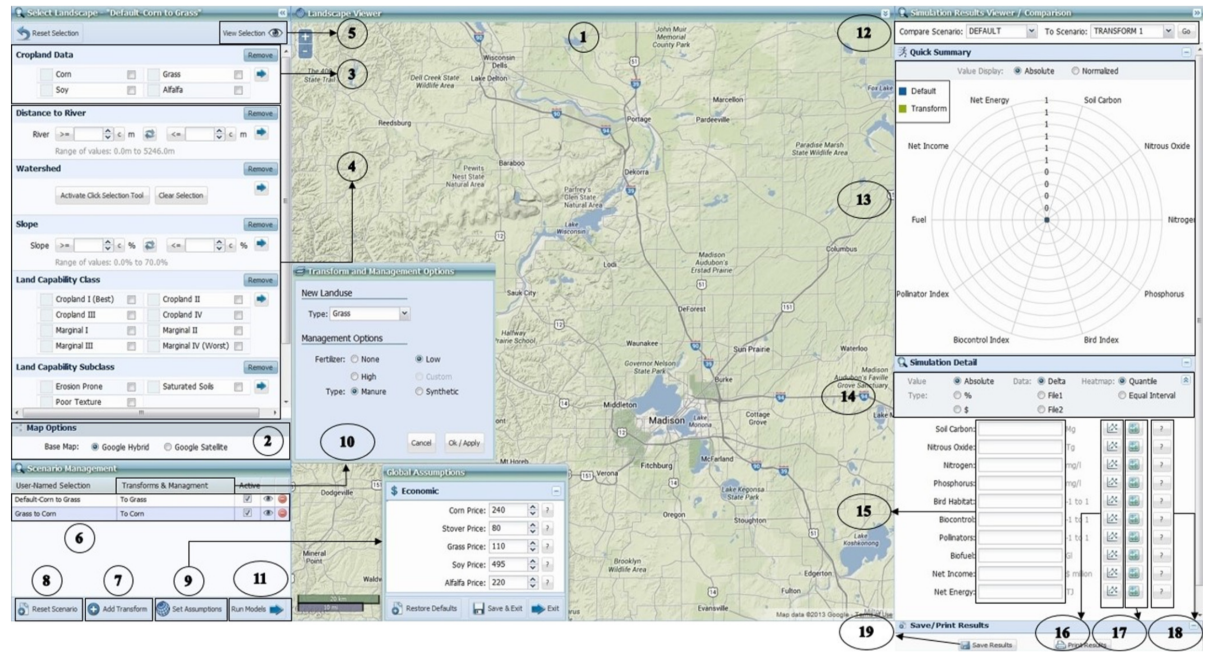

Figure 12: User interface of SmartScape [50], a tool to support policymakers.

of individual visualisation techniques found in each of these tools are presented in Section 3.3.

\subsubsection{Policymakers}

We found a total of four tools $([50,59,62,74])$ that are designed to be used by policymakers. Policymakers, such as rural extension technicians, use DSSs to facilitate the evaluation of consequences of changes in agriculture, such as crop affectations in landscapes. For instance, SmartScape [50] provides diverse visual components, such as maps and radar charts, to provide assistance to policymakers in evaluating the consequences of ecosystem services in agriculture landscapes (see Figure 12). In addition, some tools (e.g. [74]) are designed to help with information dissemination, allowing policymakers to exchange knowledge back and forth with farmers.

\subsubsection{Domain Experts}

Farm advisers, including agronomists, are considered domain experts who are often consulted by farmers, as well as by researchers for designing DSSs $[44,45,74]$. They also assist policymakers to implement farming policies and in changing farmer behaviour [93].

Farm advisers typically assess the farms by using varieties of statistical models and analysis methods, evaluating the risks of different management scenarios and finally propose strategies/guidelines for farmers. Thus, the tools designed for both farm adviser and farmers are typically capable of conducting analyses and simulations, as well as visualising the resulting guidelines for farmers (Figure 8c). There are nine tools $[36,32,30,41,52,53,57,63,65]$ that have been designed to support farm advisers. 


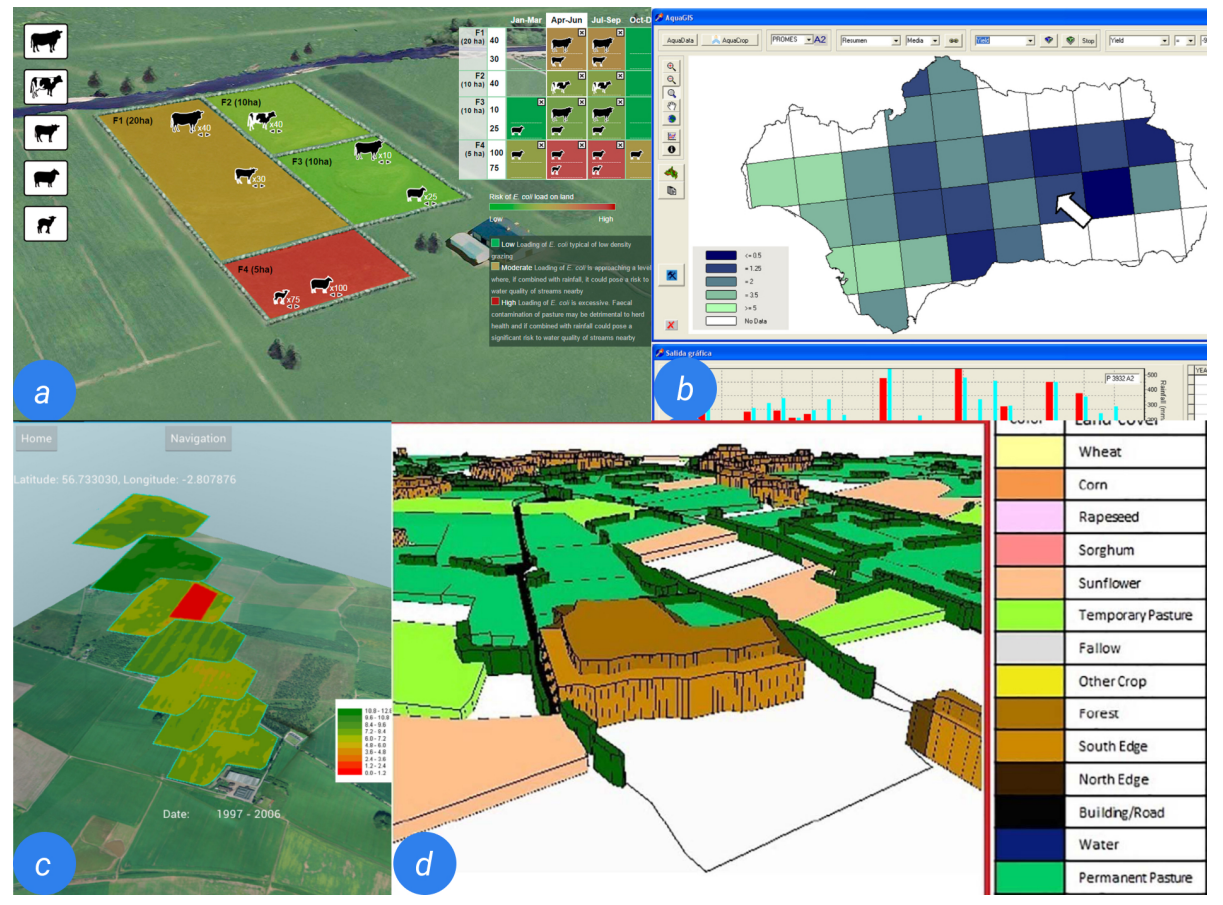

Figure 13: Examples of use of map visualisation in agriculture: a) ViPER [53], b) AQUAGIS [32], c) AgriAG [29] and d) ATLAS [33].

Agronomists, amongst all domain experts, are known for establishing good communication with farmers due to regular on-site meetings, local knowledge and long-term relationships with farmers [93]. Agronomists tend to provide practical farming decisions that are more likely to coincide with those of farmers, instead of urging new initiatives or regulations as some advisers do [93]. In this review, we found a total of four tools $[29,36,68,70]$ that have been designed to support agronomists.

\subsubsection{Academics}

We found four tools $([29,54,59,23])$ that have been designed for academics. AgriAG [29] was developed with the aid of academics that provided feedback to the elaboration of the tool. Mostly, these applications $([23,59])$ are used by academic researchers to explore new technologies to support agricultural decision-making.

\subsection{Visualisation Techniques}

Through this review, we found a number of visualisation techniques currently being used in DSSs for agriculture. Table 6 shows an exhaustive list of different visualisation techniques that are found in the papers we reviewed. In the following subsections, we present the ten most common visualisation techniques. 


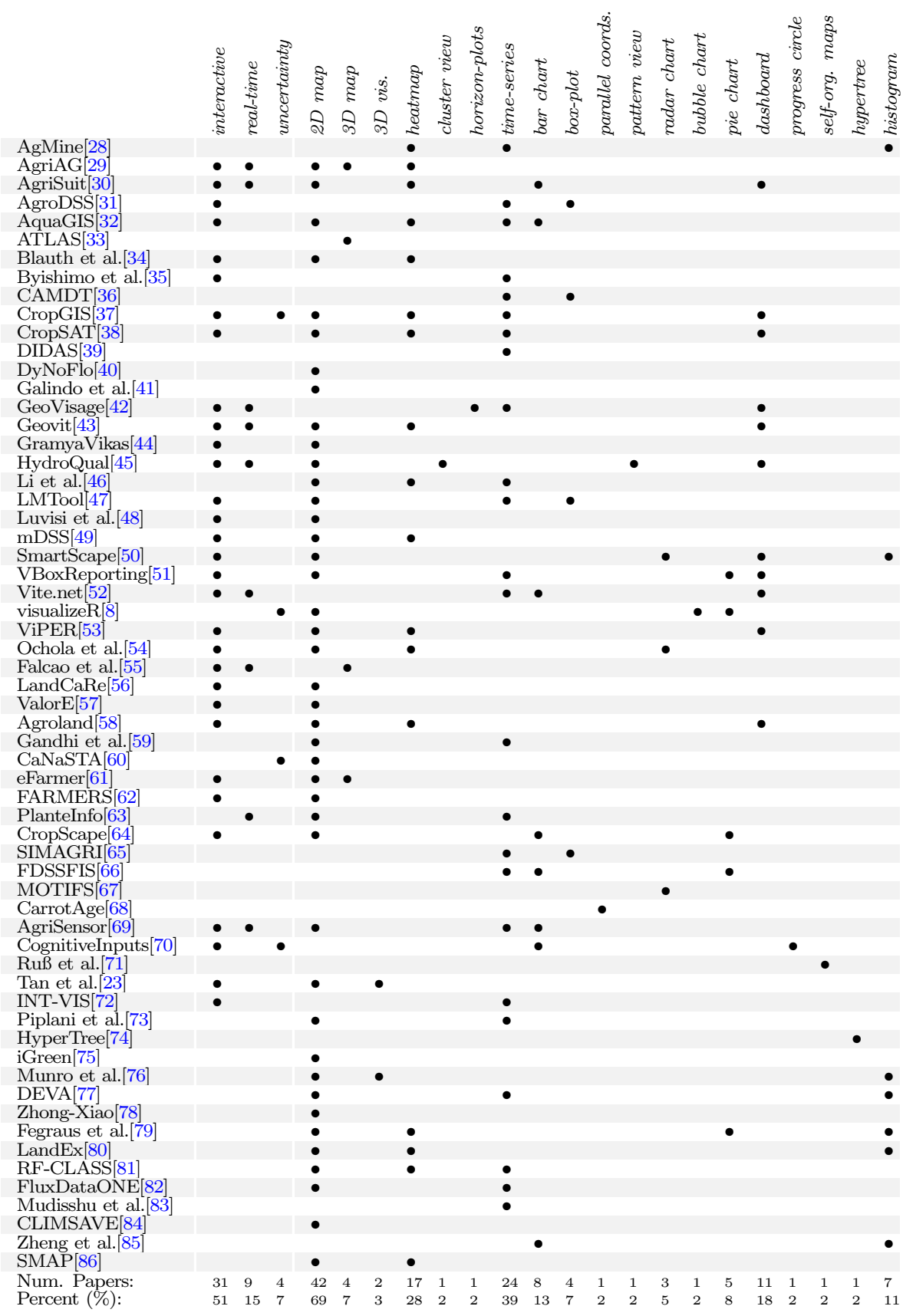

Table 6: Visualisation techniques categorised among the tools reviewed. 


\subsubsection{Map}

Maps are overwhelmingly used in agriculture to visually communicate geospatial data, providing an overview of the farms. In total, our review identified 46 papers (i.e. $75 \%$ ) that used a type of map visualisation (see Table 6 for details). As seen in Figure 13, both 2D and 3D map visualisations have been proposed to represent physical landscapes. Out of the 46 papers, a large proportion (i.e. 42 papers) have implemented 2D maps. Examples include ViPER [53] (Figure 13a) and AQUAGIS [32] (Figure 13b), where plots of physical landscapes are virtually displayed on a 2D map. Example usage of 3D maps includes AgriAG [29] (Figure 13c) and ATLAS [33] (Figure 13d). Both 2D and 3D maps are often layered with various colour representations, such as a heatmap to further visualise areas of interest in the farm.

\subsubsection{Heatmap}

Heatmaps represent data values contained in an area of interest using a colour range. Since heatmap visualisations generally highlight areas of interest, they are often used as an overlay on top of geographical maps. Heatmaps are for instance used to represent the Normalised Difference Vegetation Index (NDVI) to indicate the density of green on a patch of land. Other types of data visualised with heatmaps include biomass, weather, water density, risk of flooding, etc. We found a total of 17 tools that used heatmaps to visualise regions of interest across landscapes (see Table 6). CropSAT [38], for example, uses heatmaps to indicate biomass in a patch of farm using satellite-based images (see Figure 10). Another example is the vineyard management tool designed by Blauth and Ducati [34] (see Figure 4b) that uses a heatmap to differentiate vineyards from other vegetation, bare soil and urban areas. CAMDT [36], as shown in Figure $11 \mathrm{~b}$, uses heatmaps to indicate areas of land that are at the risk of flooding.

\subsubsection{Time-series}

Time-series visualisations are used to show a distributions of data points that are ordered by time. They are similar to line graphs in that they present two dimensional data where a sequence of time (e.g. months) is usually plotted on the $\mathrm{x}$-axis. Due to their simplicity and effectiveness in presenting data points through time, time-series are commonly seen in agricultural tools. We found a total of 24 tools (see Table 6 ) that used time-series to visualise various farm data. An example is CropGIS [37] which displays the biomass growth of a farm over time (see Figure 10). In a similar way, DIDAS [39] shows relative water uptake using time-series (see Figure 8b). Other example applications include AgMine [28], visualising wheat yield and rainfall patterns, and LMTooln [47], visualising temperature, precipitation and wind speed.

\subsubsection{Bar Chart}

Bar charts present bars clustered in groups, showing the values of more than one measured variable. One axis of bar charts shows the specific categories being compared and the other axis represents a measured value. We found a total of 
eight tools (see Table 6) that used bar charts to present data. We also discovered that, in agriculture, bar charts are commonly used in combinations with other types of visualisations. For instance, AgMine [28] (Figure 9b) uses bar charts with time-series to show average wheat yield between years. Similarly, DIDAS [39] (Figure 8b) shows water supply scheduling for irrigation over a 24-hour period. AgriSuit [30] (Figure 14c) uses a heatmap and bar chart together to present the distribution of suitable agricultural lands in an area of interest.

\subsubsection{Histogram}

Histograms are used to represent an estimate of the probability distribution of a continuous variable [94]. It differs from a bar chart in the sense that a bar graph represents categorical variables, whereas in a histogram each column/bar represents a continuous quantitative variable. We found seven tools that used histograms to present farm-related data. SmartScape [50] (Figure 12) uses a histogram to illustrate simulation results of various crop change scenarios. The results illustrated include changes in vital soil chemical contents, bird habitat, biofuel, pollinators, net income and net energy. In AquaGIS [32] (Figure 6c), a histogram is used to illustrate a comparison between crop yield and rainfall over time.

\subsubsection{Pie Chart}

A pie chart is a circular visualisation which is divided into slices with different colours to illustrate a numerical proportion. Much like bar charts, pie charts are used to visualise a distribution between categories of data. However, compared to bar charts, pie charts are less popular in agriculture. We found a total of five tools that used pie charts to visualise farm data. The VBoxReporting system [51] is an example of usage of the pie chart in agriculture. This tool uses pie charts to illustrate a comparison of work time and fuel consumption in a day between different plots.

\subsubsection{Radar Chart}

Radar charts are frequently used to visualise multivariate data in the form of a two-dimensional chart. Thus, they can be used when three or more variables are present. In agriculture, however, radar charts are less common. In this review, we discovered three tools that uses radar charts. SmartScape [50] (Figure 12) is an example tool that uses a radar chart to illustrate environmental outcomes between current and hypothetical crop change scenarios. The outcomes include vital soil chemical contents, bird habitat, biofuel, pollinators, net income and net energy. As presented in Section 3.3.5, SmartScape [50] also uses a histogram to illustrate such outcomes in two different ways.

\subsubsection{Clustering}

A clustering view shows clusters of similar information organised by colours and shapes. While clustering is a commonly used prediction technique, the visualisation of these clusters for interpretation by end-users is quite uncommon: 


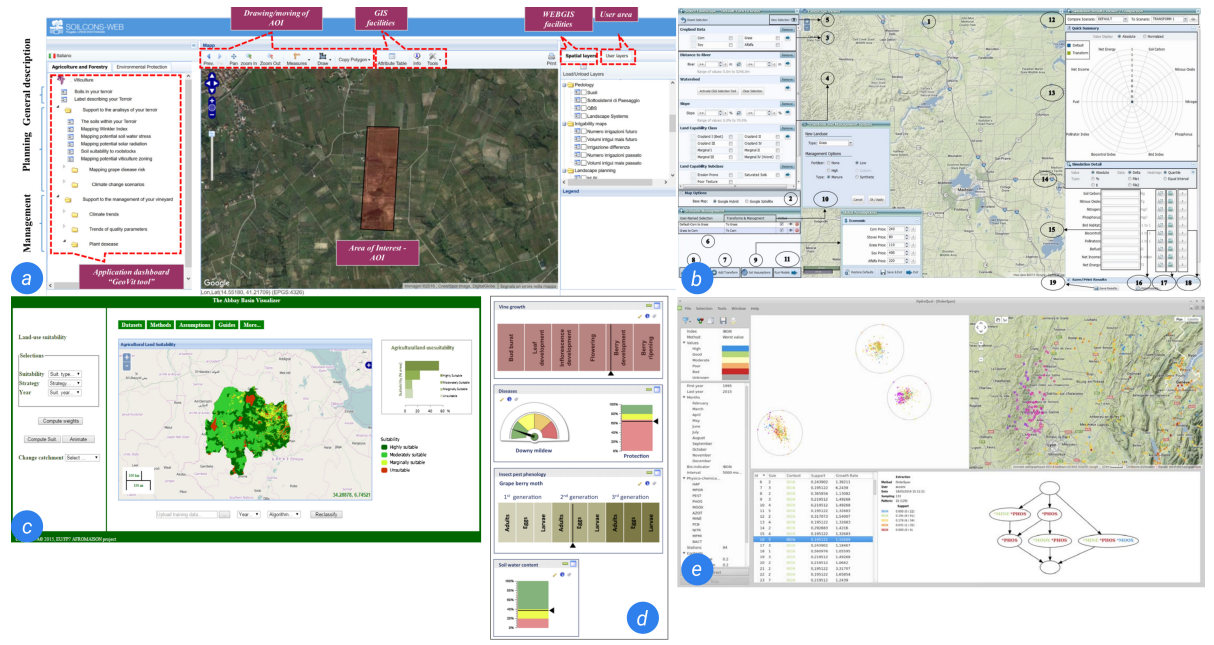

Figure 14: The use of dashboards in agriculture: a) Geovit [43], b) SmartScape [50] c) AgriSuit [30] d) Vite.net [52] e) HydroQual [45].

we found only one tool, HydroQual [45], that offers such a view. In HydroQual, water stations across a map are illustrated in groups by their behavioural similarity (see Figure 8c).

\subsubsection{Temporal Pattern View}

Also in HydroQual [45] (Figure 8c), a "temporal pattern view" is described, which is essentially a variation of a node-link diagram. It is used to illustrate patterns of changes in biological indices and physico-chemical parameters over time. In this review, we found the use of such a temporal pattern view, or node-link diagram, only in HydroQual.

\subsubsection{Dashboards}

Dashboards are a collection of visualisations that provide relevant information to be monitored on a single screen at a glance [95]. They provide an easy access to diverse visual components to display detailed data, providing a unified display to the decision-maker for interaction and exploration [96]. In this review, we identified 11 tools that use a dashboard. Figure 14 illustrates example applications of dashboards in DSSs for agriculture. Notice how all five examples in this figure have a main interface from which various other visualisations can be accessed. For instance, Geovit [43] (Figure 14a), a dashboard designed for viticulture, provides diverse interactive components surrounding a heatmap, allowing instant access to various different features. Similarly, SmartScape [50] (Figure 14b), a spatial decision support system, uses a map together with a radar chart, histograms and various diverse interactive components. AgriSuit [30] (Figure 14c), a tool for agricultural land suitability assessment, also uses a map which is augmented by heatmap and bar chart visualisations, surrounded 
by various interaction elements. HydroQual [45] (Figure 14e), a tool for visual analysis of river water quality, uses a clustering view together with a map and a pattern view. A vineyards management system, Vite.net [52] (Figure 14d), unlike the previous dashboards, does not use a map but rather a unique combination of progress bars, time-series, barometer, colour shades and decision tree.

We discovered that dashboards in agriculture are substantially used in farm management and landscape assessment tasks, with some tools (e.g. HydroQual [45]) designed for the analysis of river water quality. It appears that the primary goal of dashboards is to show an overview map to users, which is logical given that landscape is an important part of farm management. As shown in Table 6, the majority of the tools that have a dashboard (9 out of 11) use 2D maps to provide an overview of the landscape. A few other familiar visualisations used in the dashboards include heatmaps (6 tools), time-series ( 5 tools), a bar chart (2 tools), a histogram (1 tool), a radar chart (1 tool) and a pie chart (1 tool). We discovered that a few unique visualisations such as a cluster view, horizontal plots and a pattern view have also been used as part of a dashboard. Since dashboards are designed to provide a unified display to the decision-maker [96], we believe that the use of familiar visualisations is an important aspect of dashboards, especially because most end-users in agriculture are non-experts in visualisation and data analytics.

Overall, the 11 tools that have a dashboard covered the following application domains: land suitability assessment, crop biomass analysis, crop control, wheat production, fertiliser management, pest control, dairy farming and vineyard management. For the other domains such as livestock management, aquaculture analysis, cotton production, rice production and soil-moisture analysis (see Table 4), various visualisation tools exist but a dashboard has yet to be introduced. We believe that many of such domains can also greatly benefit from a dashboard. Based on an analysis of various aspects of these dashboards, we highlight opportunities for future research in Section 4.

\subsection{Interaction}

Interaction is an important aspect of visualisation tools since perception and understanding of complex data can be strongly influenced by the interactivity of a visualisation component [97]. The benefits of visualising complex data arise from being able to better interact and understand data by aggregating, filtering, searching or scaling down relevant information. Examples of interactive visualisation components can be found in various agricultural DSSs.

Thirty-one of the reviewed papers reported the use of interactive visualisations in their tools (see Table 6). Many of the reported interactive visualisations are included in dashboards, where visualisation components interact together to provide insights to user. ViPER [53] is an example tool that provides an interactive drag-and-drop interface where users can explore livestock and examine "what-if?" scenarios. Moreover, AgriSuit [30] provides an interface to allow a customised selection of weights based on user preferences to achieve better insights. Geovit [43], provides an interactive dashboard that allows the selection 
of areas of interest: based on this selection, users can explore information about soil, climate and hydrology in real-time.

\subsection{Tool Type, Platform and Development Status}

All 61 papers of this review present one or more visualisations which are designed to support various farming applications (e.g. irrigation scheduling, fertiliser application, etc.) and platforms (e.g. mobile and desktop).

We found 15 tools (see Table 7) that are designed to assist with decision support requirements by using a simulation approach. These tools allow farmers to walk-through simulated farming scenarios helping them explore and better understand their practices. On the other hand, we found 24 tools that have been designed for applications in real farming practices (i.e. non-simulation). These tools are designed to assist with decision support requirements for a particular real-world decision-making scenario, for example, irrigation scheduling or fertiliser application.

Interestingly, while a number of tools have focused on individual farming practices such as irrigation scheduling or fertiliser application, only two out of the 61 tools used visualisations to support whole-farm planning. Whole-farm planning is a difficult task, and its practices are often delivered to farmers by technicians and experts ${ }^{3}$. Whole-farm planning systems provide users with necessary tools for all the planning required for the whole farm, something farmers have to engage in nearly every day. We believe that future tools should provide farmers with various plug-and-play components allowing them to perform plannings for the whole farm or individual requirements.

In addition, we found that many of the tools have been designed to support a particular device (i.e. desktop or mobile), with the exception of two tools $[23,83]$ that were designed for both mobile and desktop devices. Overall, 30 out of the 61 tools are desktop applications while only nine are mobile applications, out of which two are designed for both desktop and mobile devices. Clearly, the support for mobile devices has been considered less frequently. However, since the scale of agricultural operations has increased over the years, it is important that the tools are scalable and support multiple devices for on-the-fly access and in-field decision-making [23].

Finally, we also discovered that while some of the tools (16 out of 61 ) are being used in practice, the majority of them (33 out of 61) are under the prototype stage (see Table 7 for details). Out of the two DSSs we discovered for whole-farm planning, only one [40] is currently available for end-users whereas the other one [57] is at the prototype stage. Similarly for the tools that are designed for mobile devices, we found only one [48] that is currently available for end-users, which again supports the argument that more tools should consider support for multiple devices for flexible decision-making [23].

\footnotetext{
${ }^{3}$ https ://www. vabeginningfarmer.alce.vt.edu/planning.html
} 


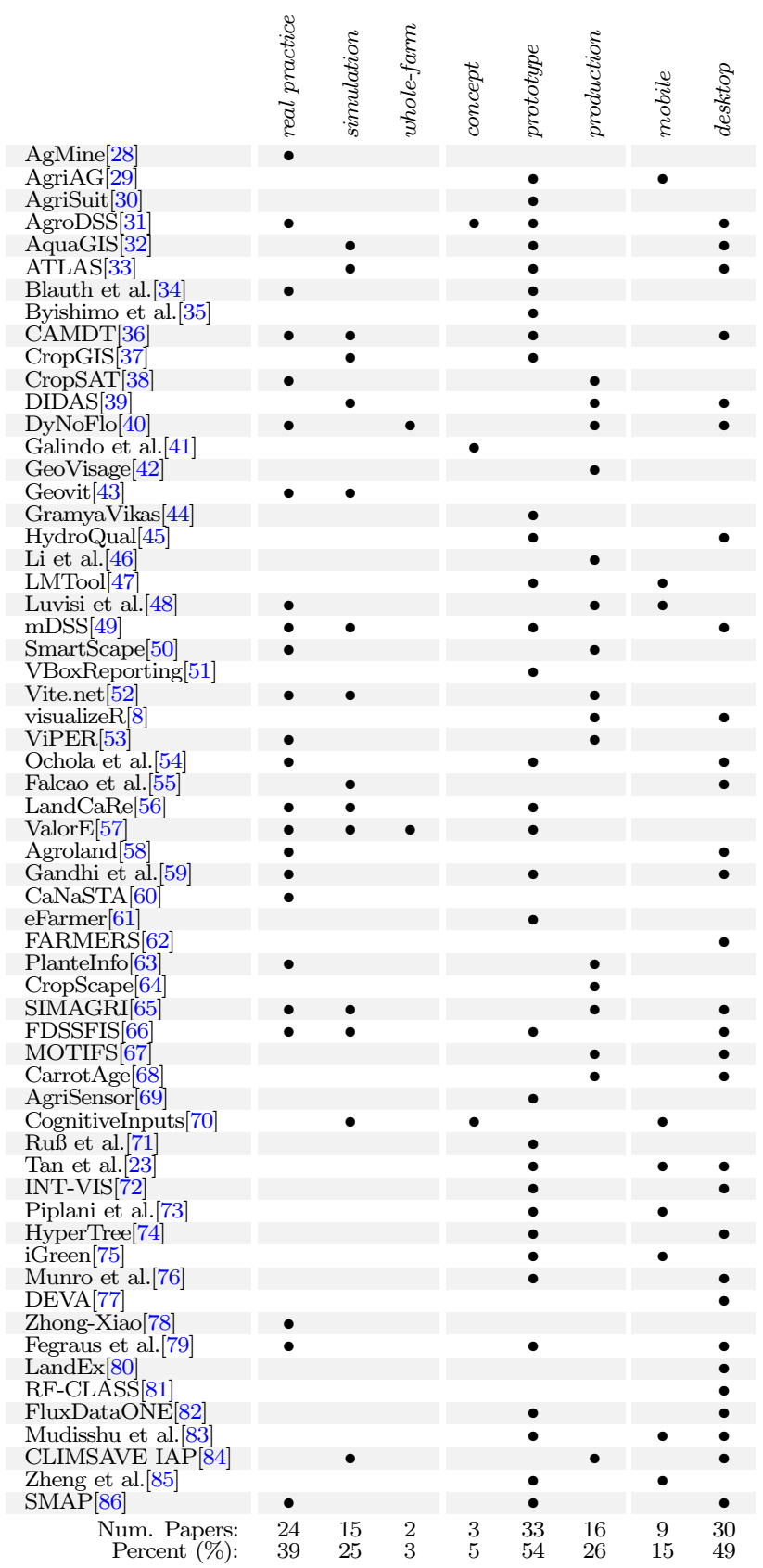

Table 7: DSSs using visualisation as categorised by tool type, development status and platform categories. Empty rows within a category mean "unclear" or "not mentioned" by the paper. 


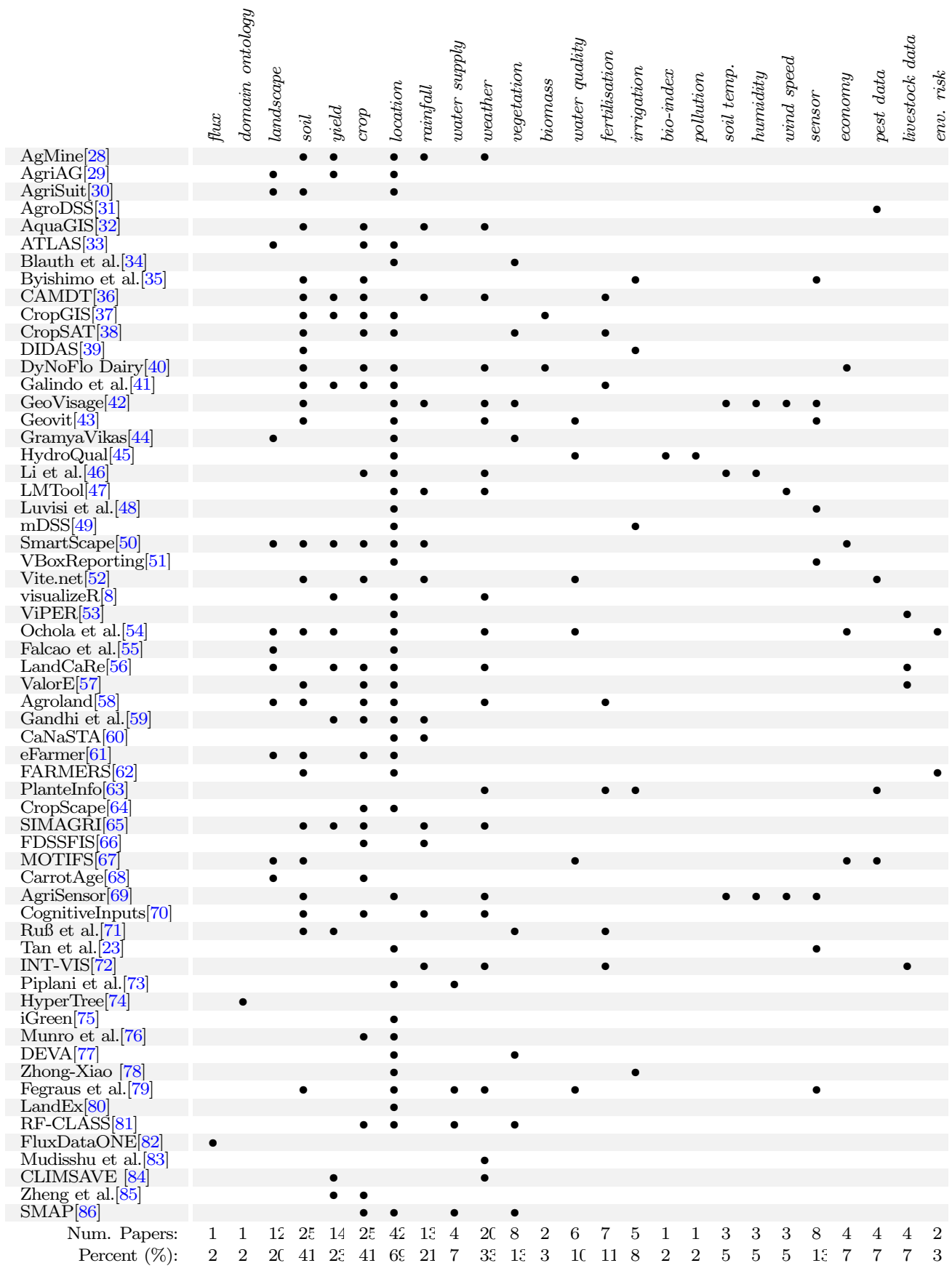

Table 8: DSS categorised by different types of data used to provide decision supports. 


\subsection{Data Source}

Since PA is driven by data to support decision-making [24], the type of data collected and how they are utilised play an important role. We found various types of data that are being used amongst the DSSs reviewed in this paper. An overview of the different types of data together with the respective DSSs is presented in Table 8.

We found that geographical data such as coordinates is the most widely used data type in agricultural visualisation. In total, we discovered 42 tools (i.e. $69 \%$ ) that used geographical data. This result is unsurprising, as we also discovered that maps are the most common type of visualisation in agriculture (see Section 3.3.1). In order to plot map visualisations, coordinates are vital. The second most common data types are soil and crop data, both having been used in 25 of the tools. Soil data usually contains vital elements for crops such as potassium, calcium, phosphorous, nitrogen, iron, magnesium, zinc, copper and $\mathrm{pH}$. Crop data often contains growth rate, species and any other data that is related to the particular crop's anatomy. Both soil and crop data, separately or together, are often used to predict additional requirements for any given farm, which includes irrigation planning, fertiliser management, environmental management, etc. SmartScape [50] (Figure 12), for example, uses both data to evaluate and compare different crop change scenarios, assisting policymakers with their decisions.

The third most commonly found data type is weather data. Our review has seen a total of 20 tools that use weather data to provide decision support. Both soil and weather play an important role for crops development. They are also unpredictable as changes can occur rapidly and without warning. Soil chemicals, for example, can vary frequently depending on animal waste on the farm. Thus, many DSSs take into account these data. As we can see in Table 8, weather and soil data are often measured by sensors. Following weather data, rainfall (13 tools) and crop yield (14 tools) have been used most frequently. Rainfall, like weather data, is vital for crops. However, rainfall alone does not determine crop development; humidity, soil temperature, etc. are also important for crops. Thus, weather data is more commonly used than rainfall alone. For instance, AquaGIS [32] uses both rainfall and weather predictions to show water levels in an area of interest, allowing for selection of a field. Crop yield, as seen in 14 tools, is often used as a metric to measure return and farm performance. In addition, four tools have also used economy data to be able to optimise resources and leverage profit.

Next, we found that landscape data is also used as an input in 12 different DSSs. The ability to hold water, for example, is greatly defined by the shape of a landscape. This, in turn, has an impact on irrigation requirements of the farm. In a few cases, irrigation data has also been used as an input for decision support. We discovered five tools that used irrigation data as an input. As discussed in Section 3.1.5, irrigation data is often used in irrigation management systems, together with additional data such as soil, location, crop type, rainfall and weather predictions (see Table 8). Similarly, there are tools designed for 
fertiliser management (7 tools) and live stock management (4 tools) which keep track of crop fertilisation and live stock data, respectively. These management tools usually illustrate the current status of a farm, allowing farmers to keep track of the impact on crops and environment. ViPER [53], for example, illustrates the risk of microbial pollution (e.g. E. Coli) on a land using livestock data. Pest control is also an important aspect of agriculture. However, we found only four tools that used pest data for decision support with pest and disease control. Interestingly, the use of pest data is only found in DSSs that are designed to assist with whole-farm management (e.g. Vite.net [52] and MOTIFS [67]).

Tools designed for other stakeholders in addition to farmers, such as farm advisers, agronomists, policymakers and academic researchers, tend to use different sets of data compared to those designed for farmers only. These data include: vegetation (8 tools), water quality (6 tools), water resources (4 tools), biomass (2 tools), environmental risk (2 tools), biological index (1 tool), pollution (1 tool), flux data (1 tool) and domain ontology (1 tool). However, as can be observed in Section 3.2, not many of the tools are designed for farm advisers, agronomists, policymakers and academic researchers; the majority of the tools are designed for farmers.

\subsection{Uncertainty}

Large amounts of unstructured data and complex predictive models are known to lead to uncertainty [98]. Given the concerns regarding trust and technology adoption in PA, the study of uncertainty assessment through visualisation is relevant to our research [99]. Visualisation mechanisms for communicating uncertainty have proven to be successful gaining trust particularly for non-expert users [92]. The incorporation of uncertainty into the decision-making process is crucial for making decisions and maximising benefits [100]. Only two out of the 61 papers considered the communication of uncertainty through visualisation: CropGIS [37] and visualizeR [8]. CropGIS [37] uses a time-series to show information about biomass development of maize with a range of uncertainty describing various meteorological scenarios (see Figure 15a). visualizeR [8] uses a bubble plot together with a map to visualise seasonal forecasting of climate, where the colour and size of the bubble are used to encode different levels of probability (see Figure 15b). Such uncertainty representations better reflect the reality compared to static forecasts, making the prediction more reliable for farmers.

\subsection{Design and Evaluation}

Despite the potential of visualisation, many approaches are poorly received by end-users, which is attributed to a lack of engagement in the design process of the tools [101]. To tackle this gap between complex scientific tools and more "user-friendly" systems, a human-centred approach is desired. In this review, we found a total of 11 articles that followed a user observation approach (see Table 9). The majority of these articles (10 out of 11) also reported using questionnaires for evaluation. In total, we found 12 articles that used questionnaires to evaluate 

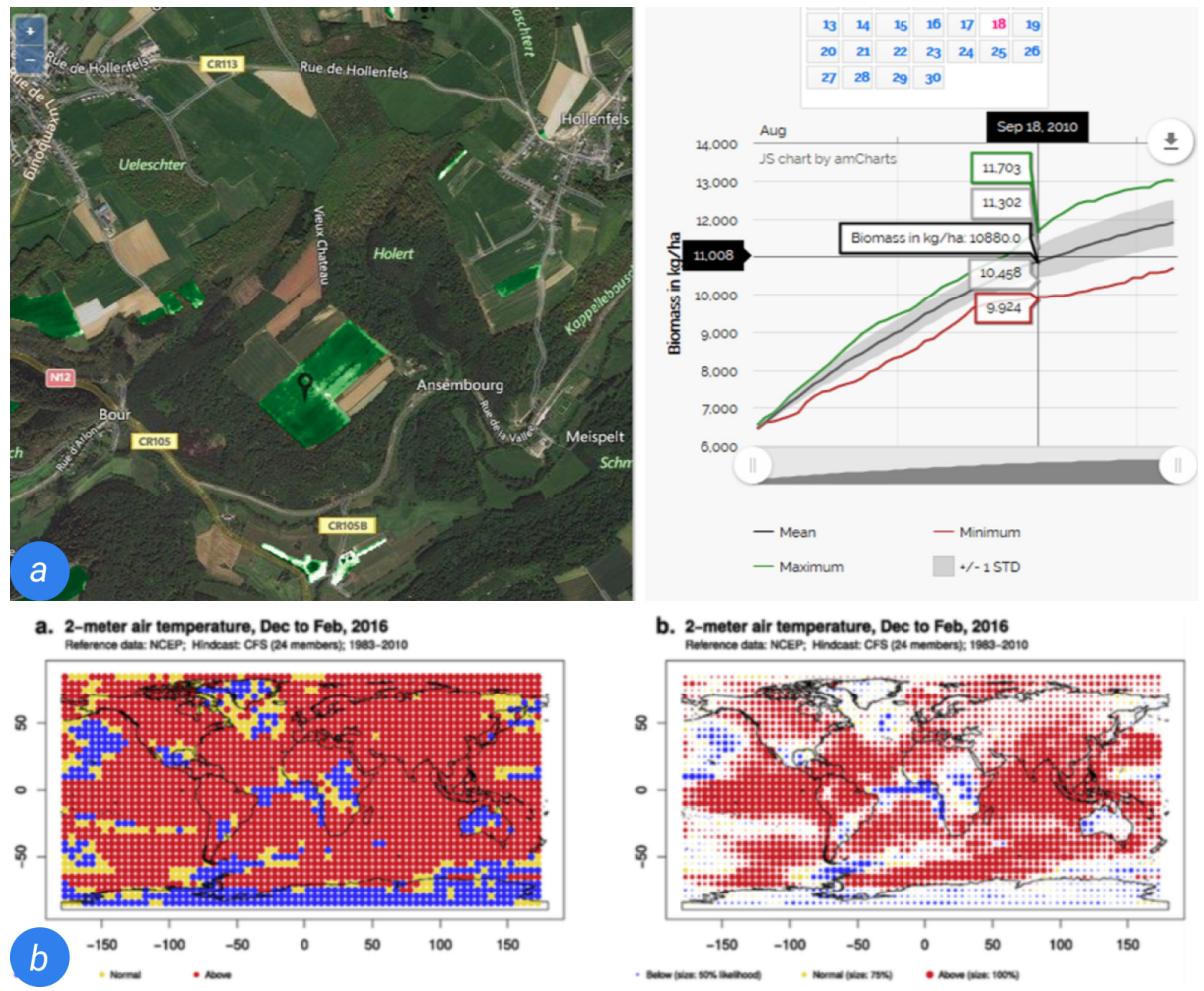

Figure 15: Visualisation of uncertainty: a) CropGIS [37] shows the variability of biomass estimation over time. b) visualiseR [8] uses bubble plot to communicate uncertainty in climate change scenarios.

their DSSs. Besides, we found that nine out of 61 articles reported using interviews as a feedback method during evaluation. Amongst these articles that used observations, questionnaires and interviews, only one (i.e. Geovisage [42]) reported the use of a qualitative analysis method, thematic analysis, to analyse feedback from end-users. Finally, we found four articles that declared the use of workshops to obtain feedback from end-users.

Participatory design has been identified as an important methodology in the design and development of tools used by end-users in the agriculture domain, with the purpose of gaining trust and technology acceptance, increasing adoption with end-users. However, only 11 out of 61 articles reported using a participatory design approach. Meanwhile, three articles used a focus group approach during the design process, and four reported the use of an iterative design approach.

\section{Discussion}

The results presented have many implications to consider for many future research directions. Here, we discuss the results around the research questions 


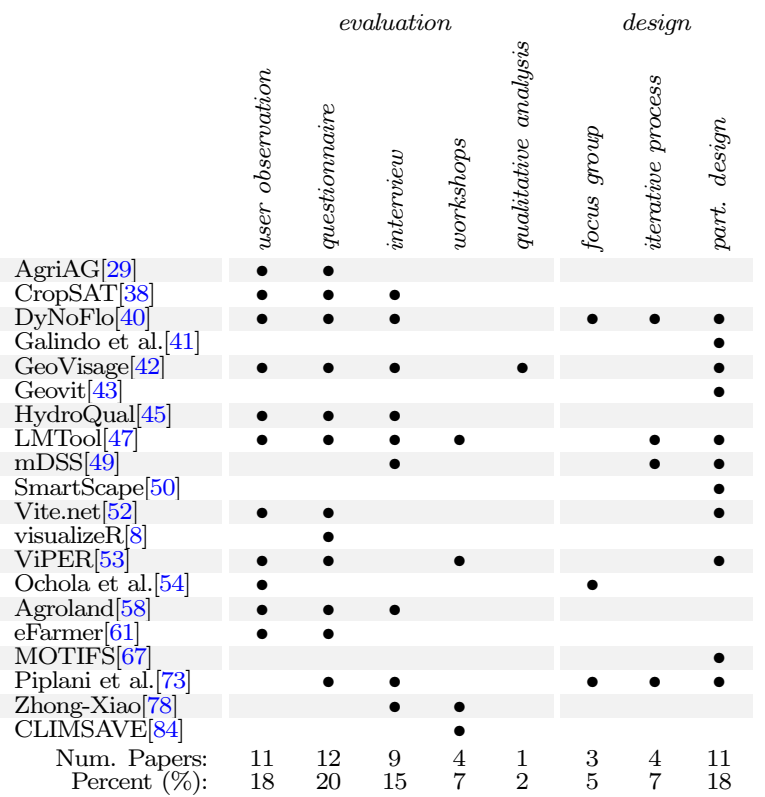

Table 9: The visualisation tools categorised by evaluation methods and design approach. Empty row within a category means "unclear" or "not mentioned" by the paper.

presented in Section 1.

\subsection{RQ1: What visualisation techniques are being used across different domains in agriculture?}

As presented in Section 3.3, the vast majority of visualisations in agriculture used a 2D map to provide an overview of the landscape to the user with a few attempts of 3D maps to provide more detail about the terrain. On top of these maps, the use of heatmaps is relevant, which are often layered over the maps to highlight different kinds of data for the user. Time-series are commonly used to display information over time, such as daily data coming from sensors. Histograms are also often used to provide information coming from sensors to show the distribution of data over time. Clustering visualisations, radar and pie charts were used to compare metrics from data in the map. Dashboards are relevant since they provide immediate access to various interactive components to monitor and display data, offering a set of visual tools to the decision-maker for interaction and exploration. We also discovered that dashboards are being used in a wide variety of application domains such as land suitability assessment, crop biomass analysis, crop control, wheat production, fertiliser management, pest control, dairy farming and vineyard management. In a number of other domains that we looked at, such as livestock management, aquaculture analysis, cotton production, rice production and soil-moisture analysis (see Table 4), dashboards are not yet introduced. We believe that these domains (but not limited to) can also greatly benefit from a dashboard. Uncertainty visualisation 
is another aspect that many existing DSSs have ignored, but can unquestionably improve user understanding of the decisions provided by the system. The role of uncertainty visualisation is further discussed in RQ3.

\subsection{RQ2: How are these visualisations being used by end-users to make deci- sions?}

Most of the applications discovered in this review are intended for farmers for various activities in the field, ranging from land suitability assessment to livestock and crop management. Some others are used by advisers and agronomists to provide feedback to farmers in their decision-making. A few of these applications are designed for policymakers who use systems to simulate conditions and plan ahead on how policies can affect particular environments. For instance, visualisation of crop status in maps allows the farmer to know the right amount of fertiliser, irrigation water or pesticide needed to achieve the optimum yield at a particular location within a parcel. Overall, three different types of DSSs were observed: those designed for a particular farming requirement, simulation and whole-farm management (see Section 3.5 for details). Unfortunately, while whole-farm management is a difficult task and is often engaged by farmers nearly every day, not many tools are currently available to support such a task. More tools should provide farmers with various plug-and-play components allowing them to perform planning for whole-farm management or individual farming requirements. Similarly, with the growth in agricultural operations over the years, we should consider designing tools that are scalable and support multiple devices (i.e. desktop and mobile) for on-the-fly access and in-field decision-making.

\subsection{RQ3: What is the role of uncertainty in the visualisation tools that support decision-making?}

Despite the importance of illustrating uncertainty in visualisations, the agriculture domain has not yet seen many applications of uncertainty visualisations. In this review, only two tools reported communication of uncertainty through visualisation. We claim that representation of uncertainty provides higher reliability and better reflection about the reality, making predictions more reliable for end-users [102] and producing high quality and informed decisions [103]. While many of the DSSs analysed in this review presented visualisations to aid stakeholders in their decision-making, they often lack an appropriate representation of uncertainty, despite this being an essential part of the decision-making process. Moreover, uncertainty has to be represented in a way that corresponds to the user's expectations and knowledge in a way that is easy to understand [104]. We believe that visualisation should be used to support the fundamental parts of the analysis, especially during uncertain scenarios, allowing users to control and evaluate data at all stages and empowering their decision-making process [105]. Presentation of uncertainty to non-expert users can be helpful, but to maximise its effectiveness it must be displayed in a way that reveals its advantages to end-users [106]. 
4.4. RQ4: What is the role of HCI in the design and development of visualisation tools to support end-user decisions?

As presented in Section 3.8, only a few tools included a report about the usability evaluation or a participatory design process. Although we have discovered a great amount of visualisation tools in agriculture, it is still a difficult task to select the most suitable visualisation and interaction techniques for end-users. Feedback from end-users is an important aspect in developing tools that are usable in practical settings $[17,18]$.

A lack of uptake of agricultural DSSs has been noted previously by researchers as a major challenge in the field [18]. The "problem of implementation" is based on the knowledge that participatory strategies during the design and development stages are the most critical factors to build technology adoption [26]. In fact, there is a significant effort to adopt a more user-centred approach in the design of DSS applications [27]. A user-centred approach in the design and development of DSSs has shown to have a positive influence, for instance, in crop production [25], being seen as a beneficial method for transferring knowledge from scientists to farmers. One of the main reasons on low adoption and acceptance is because most of the existing DSSs are based on what scientists and developers consider as the necessary knowledge that should be implemented in the tool, but in reality, they fail to capture the expertise and practical needs of the farmers. In this review, the System Usability Scale (SUS), focus groups and semi-structured interviews appeared in some of the design and development stages of applications. In particular, the case of VisAdapt presented a collaborative and interactive design process, leading to satisfactory results towards the development of the tool. Focus groups and semi-structured interviews are well-established methodologies for exploring perceptions and gathering ideas from the stakeholders which are developed as a result of the social and interactive nature of the process.

\section{Limitations}

There are some limitations to this systematic review study that should be articulated. First, our included studies were limited to those written in English, meaning that relevant studies written in other languages may have been excluded. Second, even though an extensive scope search was conducted in scientific databases and most relevant journals of the agriculture domain, some relevant literature in other domains might have been excluded. Third, we may have missed some tools that are used in practice, but that are not reported in scientific literature. Finally, some of the categories we used in this review could not be clearly identified in the papers we analysed. For example, a few papers did not clearly state the development status of the tools being presented.

\section{Conclusion}

This systematic review presents a comprehensive report on the use of visualisation techniques in the field of agriculture. We have discussed the most 
used visualisation techniques considering end-users, data sources, representation of uncertainty and evaluation methods. Based on this analysis, we have also provided design guidelines towards the implementation of interactive visual DSSs. We found that while the vast majority of applications are intended to use maps for visualisation together with satellite imagery, there is a significant opportunity of using dashboards to support farmers and advisers with more interactive components and dashboards to handle and interact with uncertain data. We also recommend the use of participatory design research, that has been successfully applied to increase the usability of applications for farmers. In addition, we highlight the role of representing uncertainty to increase user confidence and trust. The extensive body of analysed tools provide rich examples of how DSSs for agriculture can be designed on top of a variety of data sources involving different stakeholders in the design process, and representing both the data as well as underlying uncertainty to support informed decision making. We hope that this review will inspire and motivate many researchers and practitioners towards creating dashboards and visualisations following participatory research methods and uncertainty representations in future design and developments of agricultural DSSs.

\section{Acknowledgements}

Funding for this research has been provided by the European Union's Horizon 2020 research and innovation programme (grant agreement number 780751).

\section{References}

[1] M. Paustian, L. Theuvsen, Adoption of precision agriculture technologies by german crop farmers, Precision Agriculture 18 (5) (2017) 701-716. doi:10.1007/s11119-016-9482-5.

[2] A. McBratney, B. Whelan, T. Ancev, J. Bouma, Future directions of precision agriculture, Precision Agriculture 6 (1) (2005) 7-23. doi:10. 1007/s11119-005-0681-8.

[3] J. W. Jones, J. M. Antle, B. Basso, K. J. Boote, R. T. Conant, I. Foster, H. C. J. Godfray, M. Herrero, R. E. Howitt, S. Janssen, B. A. Keating, R. Munoz-Carpena, C. H. Porter, C. Rosenzweig, T. R. Wheeler, Brief history of agricultural systems modeling, Agricultural Systems 155 (2017) 240 - 254. doi:10.1016/j.agsy.2016.05.014.

[4] C. He, D. Parra, K. Verbert, Interactive recommender systems: A survey of the state of the art and future research challenges and opportunities, Expert Systems with Applications 56 (2016) 9-27.

[5] B. D. Manos, A. Ciani, T. Bournaris, I. Vassiliadou, J. Papathanasiou, A taxonomy survey of decision support systems in agriculture, Agricultural Economics Review 5 (389-2016-23416) (2004) 80. 
[6] G. Ruß, R. Kruse, M. Schneider, P. Wagner, Visualization of agriculture data using self-organizing maps, in: T. Allen, R. Ellis, M. Petridis (Eds.), Applications and Innovations in Intelligent Systems XVI, Springer London, London, 2009, pp. 47-60.

[7] M. P. Wachowiak, D. F. Walters, J. M. Kovacs, R. Wachowiak-Smolíková, A. L. James, Visual analytics and remote sensing imagery to support community-based research for precision agriculture in emerging areas, Computers and Electronics in Agriculture 143 (2017) 149 - 164. doi: 10.1016/j.compag. 2017.09.035.

[8] M. Frías, M. Iturbide, R. Manzanas, J. Bedia, J. Fernández, S. Herrera, A. Cofiño, J. Gutiérrez, An r package to visualize and communicate uncertainty in seasonal climate prediction, Environmental Modelling \& Software 99 (2018) 101 - 110. doi:10.1016/j.envsoft.2017.09.008.

[9] A. Rind, T. D. Wang, W. Aigner, S. Miksch, K. Wongsuphasawat, C. Plaisant, B. Shneiderman, Interactive information visualization to explore and query electronic health records, Found. Trends Hum.-Comput. Interact. 5 (3) (2013) 207-298. doi:10.1561/1100000039.

[10] T. V. Hertem, L. Rooijakkers, D. Berckmans, A. P. Fernández, T. Norton, D. Berckmans, E. Vranken, Appropriate data visualisation is key to precision livestock farming acceptance, Computers and Electronics in Agriculture 138 (2017) 1 -10. doi:10.1016/j.compag.2017.04.003.

[11] W. Odom, "mate, we don't need a chip to tell us the soil's dry": opportunities for designing interactive systems to support urban food production, in: Conference on Designing Interactive Systems, 2010. doi:10.1145/1858171.1858211.

[12] P. Aragó Galindo, C. Granell, P. G. Molin, J. Huerta Guijarro, Participative site-specific agriculture analysis for smallholders, Precision Agriculture 13 (5) (2012) 594-610. doi:10.1007/s11119-012-9267-4.

[13] V. Stojanovic, R. E. Falconer, J. Isaacs, D. Blackwood, D. Gilmour, D. Kiezebrink, J. Wilson, Streaming and 3d mapping of agri-data on mobile devices, Computers and Electronics in Agriculture 138 (2017) 188 199. doi:10.1016/j.compag. 2017.03.019.

[14] A. Kamilaris, A. Kartakoullis, F. X. Prenafeta-Boldú, A review on the practice of big data analysis in agriculture, Computers and Electronics in Agriculture 143 (2017) 23-37.

[15] P.-Y. Le Gal, P. Dugué, G. Faure, S. Novak, How does research address the design of innovative agricultural production systems at the farm level? a review, Agricultural systems 104 (9) (2011) 714-728. 
[16] S. A. Imam, A. Choudhary, V. K. Sachan, Design issues for wireless sensor networks and smart humidity sensors for precision agriculture: A review, in: 2015 International Conference on Soft Computing Techniques and Implementations (ICSCTI), IEEE, 2015, pp. 181-187.

[17] T. Saizmaa, H.-C. Kim, A holistic understanding of hci perspectives on smart home, in: 2008 Fourth International Conference on Networked Computing and Advanced Information Management, Vol. 2, IEEE, 2008, pp. 59-65.

[18] D. C. Rose, C. Parker, J. Fodey, C. Park, W. J. Sutherland, L. V. Dicks, Involving stakeholders in agricultural decision support systems: Improving user-centred design, International Journal of Agricultural Management $6(3-4)(2018)$ 80-89.

[19] M. D, L. A, T. J, A. DG, the PRISMA Group, Preferred reporting items for systematic reviews and meta-analyses: The prisma statement, Annals of Internal Medicine 151 (4) (2009) 264-269. doi:10.7326/ 0003-4819-151-4-200908180-00135.

[20] J. Higgins, S. Green, Handsearching, in: J. Higgins, S. Green (Eds.), Cochrane Handbook for Systematic Reviews of Interventions, Cochrane, 2005, Ch. 6 .

[21] M. L. McHugh, Interrater reliability: the kappa statistic, Biochemia medica: Biochemia medica 22 (3) (2012) 276-282.

[22] A. Dolinska, Bringing farmers into the game. strengthening farmers' role in the innovation process through a simulation game, a case from tunisia, Agricultural Systems 157 (2017) 129-139.

[23] L. Tan, R. Haley, R. Wortman, Q. Zhang, An extensible and integrated software architecture for data analysis and visualization in precision agriculture, in: 2012 IEEE 13th International Conference on Information Reuse Integration (IRI), 2012, pp. 271-278. doi:10.1109/IRI.2012.6303020.

[24] X. Pham, M. Stack, How data analytics is transforming agriculture, Business Horizons 61 (1) (2018) 125 - 133. doi:10.1016/j.bushor.2017.09. 011.

[25] C. Parker, M. Sinclair, User-centred design does make a difference. the case of decision support systems in crop production, Behaviour \& Information Technology 20 (6) (2001) 449-460.

[26] J. Lindblom, C. Lundström, M. Ljung, A. Jonsson, Promoting sustainable intensification in precision agriculture: review of decision support systems development and strategies, Precision Agriculture 18 (3) (2017) 309-331. doi:10.1007/s11119-016-9491-4. 
[27] C. Parker, A user-centred design method for agricultural dss, in: EFITA-99: Proceedings of the Second European Conference for Information Technology in Agriculture. Bonn, Germany, 1999, pp. 27-30.

[28] L. J. Armstrong, S. A. Nallan, Agricultural decision support framework for visualisation and prediction of western australian crop production (2016) 1907-1912.

URL https://ieeexplore.ieee.org/document/7724598/

[29] V. Stojanovic, R. E. Falconer, J. Isaacs, D. Blackwood, D. Gilmour, D. Kiezebrink, J. Wilson, Streaming and 3d mapping of agri-data on mobile devices, Computers and Electronics in Agriculture 138 (2017) 188 199. doi:10.1016/j.compag. 2017.03.019.

[30] S. Yalew, A. van Griensven, P. van der Zaag, Agrisuit: A web-based gismcda framework for agricultural land suitability assessment, Computers and Electronics in Agriculture 128 (2016) 1 -8. doi:10.1016/j.compag. 2016.08 .008 .

[31] R. Rupnik, M. Kukar, P. Vračar, D. Košir, D. Pevec, Z. Bosnić, Agrodss: A decision support system for agriculture and farming, Computers and Electronics in Agriculturedoi:10.1016/j.compag.2018.04.001.

[32] I. Lorite, M. García-Vila, C. Santos, M. Ruiz-Ramos, E. Fereres, Aquadata and aquagis: Two computer utilities for temporal and spatial simulations of water-limited yield with aquacrop, Computers and Electronics in Agriculture 96 (2013) 227 - 237. doi:10.1016/j.compag.2013.05.010.

[33] H. Thierry, A. Vialatte, J.-P. Choisis, B. Gaudou, H. Parry, C. Monteil, Simulating spatially-explicit crop dynamics of agricultural landscapes: The atlas simulator, Ecological Informatics 40 (2017) 62 - 80. doi:10.1016/j. ecoinf.2017.05.006.

[34] D. A. Blauth, J. R. Ducati, A web-based system for vineyards management, relating inventory data, vectors and images, Computers and Electronics in Agriculture 71 (2) (2010) 182 - 188. doi:10.1016/j.compag. 2010.01. 007.

[35] A. Byishimo, A. A. Garba, Designing a farmer interface for smart irrigation in developing countries, in: Proceedings of the 7th Annual Symposium on Computing for Development, ACM DEV '16, ACM, New York, NY, USA, 2016, pp. 30:1-30:3. doi:10.1145/3001913.3006639.

[36] E. Han, A. V. Ines, W. E. Baethgen, Climate-agriculture-modeling and decision tool (camdt): A software framework for climate risk management in agriculture, Environmental Modelling \& Software 95 (2017) 102 - 114. doi: $10.1016 / j$. envsoft .2017 .06 .024 . 
[37] M. Machwitz, E. Hass, J. Junk, T. Udelhoven, M. Schlerf, Cropgis - a web application for the spatial and temporal visualization of past, present and future crop biomass development, Computers and Electronics in Agriculturedoi:10.1016/j.compag. 2018.04.026.

[38] C. Lundström, J. Lindblom, Considering farmers' situated knowledge of using agricultural decision support systems (AgriDSS) to Foster farming practices: The case of CropSAT, Agricultural Systems 159 (C) (2018) 9-20. doi:10.1016/j.agsy.2016.09.01.

[39] S. P. Friedman, G. Communar, A. Gamliel, Didas - user-friendly software package for assisting drip irrigation design and scheduling, Computers and Electronics in Agriculture 120 (2016) 36 - 52. doi:10.1016/j.compag. 2015.11.007.

[40] V. E. Cabrera, N. E. Breuer, P. E. Hildebrand, D. Letson, The dynamic north florida dairy farm model: A user-friendly computerized tool for increasing profits while minimizing $\mathrm{n}$ leaching under varying climatic conditions, Computers and Electronics in Agriculture 49 (2) (2005) 286 308. doi:10.1016/j.compag.2005.07.001.

[41] P. Aragó Galindo, C. Granell, P. G. Molin, J. Huerta Guijarro, Participative site-specific agriculture analysis for smallholders, Precision Agriculture 13 (5) (2012) 594-610. doi:10.1007/s11119-012-9267-4.

[42] D. H. Jarvis, M. P. Wachowiak, D. F. Walters, J. M. Kovacs, Adoption of web-based spatial tools by agricultural producers: Conversations with seven northeastern ontario farmers using the geovisage decision support system, Agriculture 7 (8). doi:10.3390/agriculture7080069.

[43] F. Terribile, A. Bonfante, A. D'Antonio, R. D. Mascellis, C. D. Michele, G. Langella, P. Manna, F. Mileti, S. Vingiani, A. Basile, A geospatial decision support system for supporting quality viticulture at the landscape scale, Computers and Electronics in Agriculture 140 (2017) 88 - 102. doi:10.1016/j.compag. 2017.05.028.

[44] J. Adinarayana, S. Azmi, G. Tewari, D. Sudharsan, Gramyavikas: A distributed collaboration model for rural development planning, Computers and Electronics in Agriculture 62 (2) (2008) 128 - 140. doi:10.1016/j. compag. 2007.12.008.

[45] P. Accorsi, N. Lalande, M. Fabrègue, A. Braud, P. Poncelet, A. Sallaberry, S. Bringay, M. Teisseire, F. Cernesson, F. L. Ber, Hydroqual: Visual analysis of river water quality, in: 2014 IEEE Conference on Visual Analytics Science and Technology (VAST), 2014, pp. 123-132. doi:10.1109/VAST. 2014.7042488.

[46] M. Li, S. Chen, F. Liu, L. Zhao, Q. Xue, H. Wang, M. Chen, P. Lei, D. Wen, J. A. Sanchez-Molina, J. F. Bienvenido, Z. Li, X. Yang, A risk management 
system for meteorological disasters of solar greenhouse vegetables, Precision Agriculture 18 (6) (2017) 997-1010. doi:10.1007/s11119-017-9514-9.

[47] P. Falloon, M. B. Soares, R. Manzanas, D. San-Martin, F. Liggins, I. Taylor, R. Kahana, J. Wilding, C. Jones, R. Comer, E. de Vreede, W. S. de Cerff, C. Buontempo, A. Brookshaw, S. Stanley, R. Middleham, D. Pittams, E. Lawrence, E. Bate, H. Peter, K. Uzell, M. Richards, The land management tool: Developing a climate service in southwest uk, Climate Services 9 (2018) 86 - 100, climate services in practice: what we learnt from EUPORIAS. doi:10.1016/j.cliser.2017.08.002.

[48] A. Luvisi, M. Pagano, R. Bandinelli, E. Rinaldelli, B. Gini, M. Scartòn, G. Manzoni, E. Triolo, Virtual vineyard for grapevine management purposes: A rfid/gps application, Computers and Electronics in Agriculture 75 (2) (2011) 368 - 371. doi:10.1016/j.compag.2010.12.013.

[49] J. Mysiak, C. Giupponi, P. Rosato, Towards the development of a decision support system for water resource management, Environmental Modelling \& Software 20 (2) (2005) 203 - 214, policies and Tools for Sustainable Water Management in the European Union. doi:10.1016/j.envsoft. 2003.12.019.

[50] A. Tayyebi, T. D. Meehan, J. Dischler, G. Radloff, M. Ferris, C. Gratton, Smartscape ${ }^{\mathrm{TM}}$ : A web-based decision support system for assessing the tradeoffs among multiple ecosystem services under crop-change scenarios, Computers and Electronics in Agriculture 121 (2016) 108 - 121. doi: 10.1016/j. compag. 2015.12.003.

[51] S. Bimonte, E. Naoufal, L. Gineste, A system for the rapid design and implementation of personalized agricultural key performance indicators issued from sensor data, Computers and Electronics in Agriculture 130 (2016) 1 - 12. doi:j.compag.2016.09.010.

[52] V. Rossi, F. Salinari, S. Poni, T. Caffi, T. Bettati, Addressing the implementation problem in agricultural decision support systems: The example of vite.netR, Comput. Electron. Agric. 100 (2014) 88-99. doi: 10.1016/j.compag.2013.10.011.

[53] D. M. Oliver, P. J. Bartie, A. L. Heathwaite, L. Pschetz, R. S. Quilliam, Design of a decision support tool for visualising e. coli risk on agricultural land using a stakeholder-driven approach, Land Use Policy 66 (2017) $227-234$.

[54] W. Ochola, P. Kerkides, An integrated indicator-based spatial decision support system for land quality assessment in kenya, Computers and electronics in agriculture 45 (1-3) (2004) 3-26.

[55] A. O. Falcao, M. P. dos Santos, J. G. Borges, A real-time visualization tool for forest ecosystem management decision support, Computers and Electronics in Agriculture 53 (1) (2006) 3-12. 
[56] K.-O. Wenkel, M. Berg, W. Mirschel, R. Wieland, C. Nendel, B. Köstner, Landcare dss-an interactive decision support system for climate change impact assessment and the analysis of potential agricultural land use adaptation strategies, Journal of environmental management 127 (2013) S168-S183.

[57] M. Acutis, L. Alfieri, A. Giussani, G. Provolo, A. Di Guardo, S. Colombini, G. Bertoncini, M. Castelnuovo, G. Sali, M. Moschini, et al., Valore: An integrated and gis-based decision support system for livestock manure management in the lombardy region (northern italy), Land use policy 41 (2014) 149-162.

[58] R. Laudien, M. Pofagi, J. Roehrig, Development and implementation of an interactive spatial decision support system for decision makers in benin to evaluate agricultural land resources - case study: Agroland, International Journal of Applied Earth Observation and Geoinformation 12 (2010) S38S44.

[59] N. Gandhi, L. J. Armstrong, O. Petkar, Proposed decision support system (dss) for indian rice crop yield prediction, in: Technological Innovations in ICT for Agriculture and Rural Development (TIAR), 2016 IEEE, IEEE, 2016, pp. 13-18.

[60] R. O'Brien, Visualising uncertainty in spatial decision support, in: 8th International Symposium on Spatial Accuracy Assessment in Natural Resources and Environmental Sciences, June 2008, Shanghai, PR China, 2008.

[61] C. Pettit, I. Bishop, W. Cartwright, G. Park, O. Kemp, Enhancing webbased farm management software through the use of visualisation technologies, in: Proceedings of the MODSIM07: International Congress on Modelling and Simulation, Citeseer, 2007.

[62] M. Río, A. Franco-Uría, E. Abad, E. Roca, A risk-based decision tool for the management of organic waste in agriculture and farming activities (farmers), Journal of hazardous materials 185 (2-3) (2011) 792-800.

[63] I. Thysen, N. K. Detlefsen, Online decision support for irrigation for farmers, Agricultural Water Management 86 (3) (2006) 269 - 276. doi: $10.1016 / j$. agwat. 2006.05.016.

[64] W. Han, Z. Yang, L. Di, R. Mueller, Cropscape: A web service based application for exploring and disseminating us conterminous geospatial cropland data products for decision support, Computers and Electronics in Agriculture 84 (2012) 111-123.

[65] E. Han, W. E. Baethgen, A. V. Ines, F. Mer, J. S. Souza, M. Berterretche, G. Atunez, C. Barreira, Simagri: An agro-climate decision support tool, Computers and Electronics in Agriculture. 
[66] G. Yang, L. Liu, P. Guo, M. Li, A flexible decision support system for irrigation scheduling in an irrigation district in china, Agricultural water management 179 (2017) 378-389.

[67] M. Meul, S. Van Passel, F. Nevens, J. Dessein, E. Rogge, A. Mulier, A. Van Hauwermeiren, Motifs: a monitoring tool for integrated farm sustainability, Agronomy for sustainable development 28 (2) (2008) 321332 .

[68] F. Le Ber, M. Benoît, C. Schott, J.-F. Mari, C. Mignolet, Studying crop sequences with carrotage, a hmm-based data mining software, Ecological modelling 191 (1) (2006) 170-185.

[69] P. Kubicek, J. Kozel, R. Stampach, V. Lukas, Prototyping the visualization of geographic and sensor data for agriculture, Computers and Electronics in Agriculture 97 (2013) 83 - 91. doi:10.1016/j.compag. 2013.07.007.

[70] S. K. Devitt, T. Perez, D. Polson, T. R. Pearce, R. Quagliata, W. Taylor, D. Thornby, J. Beekhuyzen, A cognitive decision tool to optimise integrated weed management, in: International Tri-Conference for Precision Agriculture 2017, Hamilton, New Zealand, 2017.

[71] G. Ruß, R. Kruse, M. Schneider, P. Wagner, Visualization of agriculture data using self-organizing maps, in: T. Allen, R. Ellis, M. Petridis (Eds.), Applications and Innovations in Intelligent Systems XVI, Springer London, London, 2009, pp. 47-60.

[72] S. Gibbs, K. Cromie, R. Pellow, An interactive spreadsheet model for visualizing dairy farm data, in: Proceedings of the 15th New Zealand Conference on Human-Computer Interaction, ACM, 2015, pp. 51-55.

[73] D. Piplani, D. K. Singh, K. Srinivasan, N. Ramesh, A. Kumar, et al., Digital platform for data driven aquaculture farm management, in: Proceedings of the 7th International Conference on HCI, IndiaHCI 2015, ACM, 2015, pp. 95-101.

[74] K. X. de Souza, A. D. dos Santos, S. R. Evangelista, Visualization of ontologies through hypertrees, in: Proceedings of the Latin American conference on Human-computer interaction, ACM, 2003, pp. 251-255.

[75] A. Ebert, M. Deller, S. Thelen, I. Scheler, igreen: non-formal modelling in practice, in: Proceedings of the 29th Annual European Conference on Cognitive Ergonomics, ACM, 2011, pp. 283-284.

[76] H. Munro, K. Novins, G. Benwell, A. Mowat, Interactive visualisation tools for analysing nir data, in: Computer-Human Interaction, 1996. Proceedings., Sixth Australian Conference on, IEEE, 1996, pp. 19-24. 
[77] B. Reed, D. Swets, L. Bard, J. Brown, J. Rowland, Interactive visualization of vegetation dynamics, in: Geoscience and Remote Sensing Symposium, 2001. IGARSS'01. IEEE 2001 International, Vol. 1, IEEE, 2001, pp. 210212.

[78] Z.-X. Leng, H. Yimit, Decision support systems for improving irrigation scheme management in arid area, in: Education Technology and Computer Science, 2009. ETCS'09. First International Workshop on, Vol. 3, IEEE, 2009, pp. 332-335.

[79] E. H. Fegraus, I. Zaslavsky, T. Whitenack, J. Dempewolf, J. A. Ahumada, K. Lin, S. J. Andelman, Interdisciplinary decision support dashboard: A new framework for a tanzanian agricultural and ecosystem service monitoring system pilot, IEEE Journal of Selected Topics in Applied Earth Observations and Remote Sensing 5 (6) (2012) 1700-1708.

[80] T. F. Stepinski, P. Netzel, J. Jasiewicz, Landex - a geoweb tool for query and retrieval of spatial patterns in land cover datasets, IEEE Journal of Selected Topics in Applied Earth Observations and Remote Sensing 7 (1) (2014) 257-266.

[81] B. Zhang, L. Di, G. Yu, Y. Shao, R. Shrestha, L. Kang, A web service based application serving vegetation condition indices for flood crop loss assessment, in: Agro-Geoinformatics (Agro-Geoinformatics), 2013 Second International Conference on, IEEE, 2013, pp. 215-220.

[82] A. Yan, B. Lv, F. Liu, Q. Li, G. Lin, Y. Bai, Fluxdataone: An integrated solution for the management, visualization, and analysis of flux data for agricultural and ecological studies, IEEE Journal of Selected Topics in Applied Earth Observations and Remote Sensing 7 (11) (2014) 4523-4529.

[83] A. Mudisshu, T. Murase, S. Otsuka, Meteorological data visualization application for mandarin farmers support, in: Advanced Applied Informatics (IIAI-AAI), 2016 5th IIAI International Congress on, IEEE, 2016, pp. 900-903.

[84] C. Savin, Embedding sectorial models in an integrated platform for assessing climate change impacts, in: Modelling Symposium (EMS), 2015 IEEE European, IEEE, 2015, pp. 37-42.

[85] Y. Zheng, T. Altamimi, Innovative mobile visualization platform: Specification on a prototype mobile application for agriculture, in: Cybernetics (CYBCONF), 2017 3rd IEEE International Conference on, IEEE, 2017, pp. 1-6.

[86] L. Hu, L. Di, E. Yu, P. Yue, J. Tang, L. Lin, C. Zhang, Z. Sun, R. Hu, R. Shrestha, et al., Developing geospatial web service and system for smap soil moisture monitoring, in: Agro-Geoinformatics, 2017 6th International Conference on, IEEE, 2017, pp. 1-5. 
[87] S. Best, L. León, M. Claret, Use of precision viticulture tools to optimize the harvest of high quality grapes, Proceedings of the fruits and nuts and vegetable production engineering TIC (Frutic05) (2005) 249-258.

[88] I. M. del Águila, J. Cañadas, S. Túnez, Decision making models embedded into a web-based tool for assessing pest infestation risk, Biosystems Engineering 133 (2015) 102 - 115. doi:j.biosystemseng.2015.03.006.

[89] A. McBratney, B. Whelan, T. Ancev, J. Bouma, Future directions of precision agriculture, Precision agriculture 6 (1) (2005) 7-23.

[90] D. Spiegelhalter, M. Pearson, I. Short, Visualizing uncertainty about the future, science 333 (6048) (2011) 1393-1400.

[91] D. A., P. L., D. C., M. K., R. J., G. M.E., B. S., Albero: A visual analytics approach for probabilistic weather forecasting, Computer Graphics Forum 36 (7) (2017) 135-144. doi:10.1111/cgf.13279.

[92] M. Kay, T. Kola, J. R. Hullman, S. A. Munson, When (ish) is my bus?: User-centered visualizations of uncertainty in everyday, mobile predictive systems, in: Proceedings of the 2016 CHI Conference on Human Factors in Computing Systems, CHI '16, ACM, New York, NY, USA, 2016, pp. 5092-5103. doi:10.1145/2858036.2858558.

[93] J. Ingram, Agronomist-farmer knowledge encounters: an analysis of knowledge exchange in the context of best management practices in england, Agriculture and Human Values 25 (3) (2008) 405-418. doi: $10.1007 / \mathrm{s} 10460-008-9134-0$. URL https://doi.org/10.1007/s10460-008-9134-0

[94] K. Pearson, Contributions to the mathematical theory of evolution. ii. skew variation in homogeneous material, Philosophical Transactions of the Royal Society of London 186 (Part I) (1895) 343-424.

[95] S. Few, Information dashboard design, O'Reilly Sebastopol, CA, 2006.

[96] B. Saket, A. Endert, C. Demiralp, Task-based effectiveness of basic visualizations, IEEE Transactions on Visualization and Computer Graphics.

[97] E. Zudilova-Seinstra, T. Adriaansen, R. Van Liere, Overview of interactive visualisation, in: Trends in Interactive Visualization, Springer, 2009, pp. $3-15$.

[98] M. Daradkeh, A. McKinnon, C. Churcher, Visualisation tools for exploring the uncertainty-risk relationship in the decision-making process: a preliminary empirical evaluation, in: Proceedings of the Eleventh Australasian Conference on User Interface-Volume 106, Australian Computer Society, Inc., 2010, pp. 42-51. 
[99] M. Marra, D. J. Pannell, A. A. Ghadim, The economics of risk, uncertainty and learning in the adoption of new agricultural technologies: where are we on the learning curve?, Agricultural Systems 75 (2) (2003) 215 - 234. doi:10.1016/S0308-521X(02)00066-5.

[100] M. Daradkeh, B. Abul-Huda, Incorporating uncertainty into decisionmaking: An information visualisation approach, in: I. Linden, S. Liu, C. Colot (Eds.), Decision Support Systems VII. Data, Information and Knowledge Visualization in Decision Support Systems, Springer International Publishing, Cham, 2017, pp. 74-87.

[101] C. J. Whitman, G. Armijo, L. N. Schiappacasse, Methodology for informed design of sustainable tourism accommodation in chile's 9th region the gateway to patagonia, Energy Procedia 78 (2015) 267 - 272, 6th International Building Physics Conference, IBPC 2015. doi:10.1016/j.egypro. 2015. 11.633 .

[102] D. Sacha, H. Senaratne, B. C. Kwon, G. Ellis, D. A. Keim, The role of uncertainty, awareness, and trust in visual analytics, IEEE transactions on visualization and computer graphics 22 (1) (2016) 240-249.

[103] M. Fernandes, L. Walls, S. Munson, J. Hullman, M. Kay, Uncertainty displays using quantile dotplots or cdfs improve transit decision-making, in: Proceedings of the 2018 CHI Conference on Human Factors in Computing Systems, ACM, 2018, p. 144.

[104] B. c. Kwon, B. Fisher, J. S. Yi, Visual analytic roadblocks for novice investigators, in: 2011 IEEE Conference on Visual Analytics Science and Technology (VAST), 2011, pp. 3-11. doi:10.1109/VAST.2011.6102435.

[105] M. John, S. Koch, F. Heimerl, A. Müller, T. Ertl, J. Kuhn, Interactive visual analysis of german poetics, Digital Humanities.

[106] C. Kinkeldey, J. Schiewe, H. Gerstmann, C. Götze, O. Kit, M. Lüdeke, H. Taubenböck, M. Wurm, Evaluating the use of uncertainty visualization for exploratory analysis of land cover change: A qualitative expert user study, Computers \& Geosciences 84 (2015) 46 - 53. doi:10.1016/j . cageo. 2015.08 .007 . 